Cómo citar este trabajo: Solís Trapero, E., Ruiz Apilánez, B., García Camacha Gutiérrez, I., Ureña Francés, J. M., \& Mohíno Sanz, I. (2019). El enfoque morfogenético y cuantitativo aplicado al estudio de las formas urbanas y la diversidad funcional: el caso de Toledo. Boletín de la Asociación de Geógrafos Españoles, 82, 2753, 1-45. http://dx.doi.org/10.21138/bage.2753

\title{
El enfoque morfogenético y cuantitativo aplicado al estudio de las formas urbanas
} y la diversidad de usos: el caso de Toledo

The morphogenetic and quantitative approach applied to the study of urban forms and land-use mix: the case of Toledo

\author{
Eloy Solís Trapero \\ eloy.solis@uclm.es \\ Departameto de Ingenería Civil y la Edificación \\ Universidad de Castilla-La Mancha (España) \\ Borja Ruiz-Apilánez \\ Borja.RuizApilanez@uclm.es \\ Departameto de Ingenería Civil y la Edificación \\ Universidad de Castilla-La Mancha (España) \\ Irene García Camacha Gutiérrez \\ Irene.GarciaCamacha@uclm.es \\ Departamento de Matemáticas \\ Universidad de Castilla-La Mancha (España) \\ José María Ureña Francés \\ josemaria.urena@uclm.es \\ Departameto de Ingenería Civil y la Edificación \\ Universidad de Castilla-La Mancha (España)
}




\author{
Inmaculada Mohíno Sanz \\ inmaculada.mohino@upm.es \\ Departamento de Urbanística y Ordenación del Territorio \\ Universidad Politécnica de Madrid (España)
}

\title{
Resumen
}

Tradicionalmente, la forma urbana se ha usado como medio para entender los espacios urbanos. A pesar de ello, este conocimiento se ha efectuado especialmente en cascos antiguos y grandes ciudades, y el alcance de sus enfoques y métodos ha sido muy limitado en planificación y diseño. En base a estas limitaciones el artículo plantea (a) la identificación y caracterización de formas urbanas de los nuevos paisajes urbanos contemporáneos apoyándose en un enfoque morfogenético, y (b) la evaluación de la influencia en la configuración espacial sobre la diversidad de usos apoyándose en el enfoque cuantitativo. Mientras que un enfoque morfogenético revela diferentes formas urbanas con relación a la configuración espacial de las manzanas, parcelas, edificios, calles, plazas y zonas verdes, el enfoque cuantitativo, apoyado en las técnicas spacemate, diagrama n y el modelo de mezcla urbana funcional nos informa de propiedades espaciales de las formas urbanas y, a través del análisis factorial e inferencial, nos ayuda a evaluar la influencia de dichas propiedades en la diversidad de usos. Este artículo contribuye al debate conceptual y combinación de métodos en el estudio del grado de influencia del espacio (forma urbana) en la actividad humana (diversidad de usos) sirviendo además para guiar la planificación y diseño urbanos.

Palabras clave: formas urbanas; diversidad de usos; catastro; sistemas de información geográfica; Toledo.

\begin{abstract}
Traditionally, urban form has been used to understand urban spaces. However, this knowledge has mainly focused on historic city centers and large cities, and the scope of their approaches and methods has been very limited in the planning practice and urban design. Based on these limitations, the article proposes (a) the identification and characterization of urban forms of new contemporary urban landscapes based on a morphogenetic approach, and (b) the evaluation of the influence of spatial configuration on land-use mix based on a quantitative approach. On the one hand, the morphogenetic approach reveals different urban forms in relation to the spatial configuration of blocks, plots, buildings, streets, plazas and green areas. On the other, the quantitative approach, supported by the spacemate technique, the $n$ diagram and the functional urban mix model, firstly informs us of the spatial properties of urban forms and secondly, through factorial and inferential analyses, helps us to evaluate the
\end{abstract}


influence of these properties on the diversity of uses. To sum up, this article contributes to the conceptual debate and combination of methods in the study of the degree of influence of space (urban form) on human activity (land use mix) but also serves to guide urban planning and design.

Key words: urban forms; mixed land use; cadaster; geographical information system; Toledo.

\section{Introducción}

Los debates acerca de la recuperación del centro de la ciudad, la promoción de la compacidad, el freno a la dispersión como respuesta a la movilidad motorizada, la reducción del consumo energético, el retroceso de suelos de valor agroforestal, etc. Uacobs \& Appleyard, 1982; Cervero, 1998; EEA, 2006; European Commission, 2011; Jacobs, 2011; Capel, 2016), han puesto sobre la mesa la necesidad de reexaminar las formas urbanas existentes, estudiar sus rasgos espaciales y entender cómo ellos influyen e interaccionan con la dinámica y funcionamiento de la ciudad (Colquhoun, 1989; Duany, Plater-Zyberk \& Speck, 2000; Berghauser \& Haup, 2007; Kropf, 2016). En este contexto, diversos investigadores Madanipour (2006), Kropf (2011), Gil et al. (2012) o Ding (2013), demandan que el corpus de conocimiento de la teoría y práctica del urbanismo se apoye en evidencias científicas, es decir, necesitamos una asimilación crítica del conocimiento científico en el contexto de los procesos de desarrollo urbano y que los fundamentos científicos soporten una conexión entre planificadores, promotores, diseñadores y usuarios de la ciudad.

Cada vez más se vuelve necesario ampliar el conocimiento y hacerlo más preciso sobre las formas urbanas de los paisajes contemporáneos, tanto a escala urbana como metropolitana (Maller, 1998; Panerai et al., 1999). Como señalan Lopez de Lucio et al. (2016, p. 14) en el estudio sobre forma urbana han dominado "descripciones históricas sobre el crecimiento de la ciudad, sus sucesivas fases de expansión planeada o espontánea -vinculado a la genealogía urbanística-, los mecanismos privados de promoción y públicos de control -lógica promocional unitaria, concertada, etc. -, las determinaciones geográficas, económicas o políticas que inciden en los distintos estadios de crecimiento urbano, etc.; sin embargo, son raros los trabajos publicados que describen y analizan de forma metódica formas o morfología urbanas concretas". Continúan los autores, "cuando esto sucede, suelen centrarse en la descripción aislada de edificios concretos, en el estilo de los edificios, canon compositivo externo, formas de distribución en planta, tecnología constructiva, etc." En este sentido, necesitamos un método homogéneo que ayude a identificar y reconocer formas urbanas desde la configuración y relaciones espaciales que tienen los elementos o componentes físicos básicos que las constituyen (véase Figura 1).

La necesidad de analizar las formas urbanas se apoya en la idea de que las propiedades espaciales de cada morfología condicionan la vitalidad urbana como, por ejemplo, la mezcla urbana de usos. Lejos de la doctrina programática tradicional necesitamos aportar conocimiento sobre el grado de 
urbanidad del espacio urbano. Se trata de identificar el conjunto de propiedades o cualidades espaciales que debe tener un espacio para convertirse en un lugar vivo, diverso y dinámico (Montgomery, 1998; Netto, 2017).

Figura 1. Componentes básicos de la forma urbana

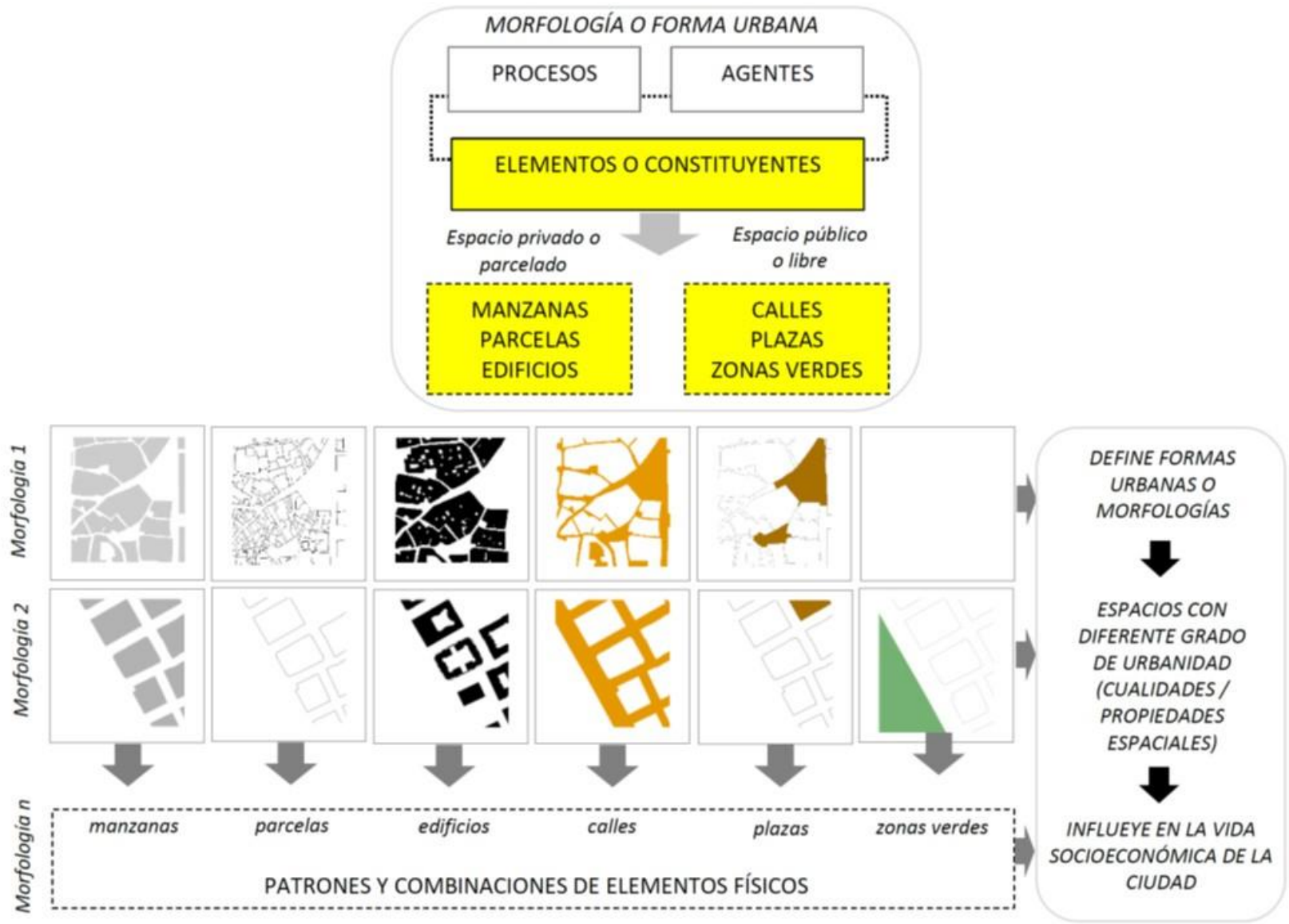

Fuente: elaboración propia

Nuestra hipótesis es que estas propiedades pueden buscarse para cada lugar desde un análisis cuantitativo de las formas urbanas existentes. Con el fin de contrastar este planteamiento proponemos combinar el enfoque morfogenético y el enfoque cuantitativo para dar respuesta a dos objetivos. El primero, identificar y delimitar las formas urbanas existentes conforme a categorías morfogenéticas. El segundo, establecer un conjunto de parámetros espaciales útiles que son susceptibles de ser medidos cuantitativamente y permiten evaluar la incidencia de la configuración espacial en la incidencia en la mezcla de usos en la ciudad.

El análisis morfológico de los tejidos urbanos permite entender la lógica de su transformación (MaratMendes, 2013; Oliverira, 2016), es decir, de los aspectos tecnológicos, culturales y económicos ligados a los aspectos físicos, de la forma. Para ello el análisis empleará herramientas y técnicas recientemente desarrolladas para entender la interdependencia entre forma urbana y vida social y, en consecuencia, orientar la planificación y diseño urbano (Berhauser \& Haup, 2010; Harper, 2013; Oliveira, 2013; Kropf, 2016). La principal contribución de este artículo es complementar el análisis 
morfológico evaluando la influencia de la configuración espacial en la mezcla de usos, ya que hasta la fecha los estudios sobre medición de mezcla de usos se han centrado en conocer la diversidad previa de actividades, la localización en la ciudad -tanto respecto al centro como a otros usos- y la cantidad - ¿̇cuál es la cantidad y proximidad de un tipo de suelo a otro? - (van den Hoek, 2009; Clifton et al., 2008; Carpio et al., 2018) y menos en los rasgos espaciales que influyen en la ubicación. Cuando esto sucede, los elementos morfológicos se consideran de forma aislada (Ye \& van Ness, 2014).

Utilizando la cartografía digital catastral -capa de manzanas, parcelas, edificios y sistema de espacios públicos-, fotografía aérea y planes de ordenación municipal como fuentes de información, se propone el uso de los Sistemas de Información Geográfica (SIG) para delimitar ámbitos y calcular datos básicos relativos a propiedades espaciales de estas formas físicas - superficie ocupada, edificada, espacio libre público y privado, etc.-. Para realizar este trabajo se toma como caso de estudio Toledo, ciudad de tamaño medio en el sistema urbano español.

Conforme a lo anterior, el artículo se organiza del siguiente modo. En el apartado 2 se describe el marco teórico que justifica el enfoque morfogenético y cuantitativo en el estudio de la forma urbana y su influencia en la vida y funcionamiento de la ciudad. En el apartado 3 se define el procedimiento, las variables e indicadores utilizados. Tras ello, en el apartado 4 se presentan los resultados obtenidos, en el apartado 5 se efectúa una discusión de los resultados y se establecen las conclusiones.

\section{Marco teórico}

Identificar o reconocer formas urbanas no es una tarea sencilla. Como han señalado algunos autores Kropf $(2016,2009)$ o Prosperi et al. (2009) el debate e investigación sobre la identificación de formas urbanas está ligado al proceso de selección, unión y separación de ciertos elementos físicos y socioeconómicos, a la escala o nivel de resolución que adoptamos, pero también a la información disponible y a las técnicas utilizadas.

A pesar del reconocimiento y uso de diferentes categorías a la hora de identificar formas urbanas, véase las categorías históricas 1 , las categorías funcionales ${ }^{2}$ y las categorías normativas ${ }^{3}$, las más

1 La ciudad antigua, la ciudad romana, la ciudad islámica, la ciudad medieval, la ciudad renacentista, la ciudad del diecinueve, la ciudad del suburbio del siglo XX, etc. (Chueca, 1968; Sicca, 1981; Wall \& Waterman, 2012);

2 Los centros de negocios, los espacios residenciales, los espacios industriales, los polos tecnológicos, las ciudades universitarias, los ejes logísticos, los espacios de oficina, los centros comerciales, etc. (Beaujeu-Garnier \& Chabot, 1970; López de Lucio, 1993; Enguita, 2008; Cebrián \& Panadero, 2013). Aplicado a las nuevas áreas de expansión, estas categorías son tipificadas en función de la ocupación y forma que ocupan en el territorio. Por ejemplo, Antoni Font (2007) diferencia entre: filamentos, difusiones, ocupaciones puntuales, urbanizaciones, etc.

3 Basados en indicadores orientados a guiar aspectos específicos del planeamiento y el diseño urbano, tales como compacidad, densidad, diversidad, diseño solar, zonas verdes, consumo de energía, etc.- (Duany, 2002; Jabareen, 2006, Bohl \& Plater-Zyberk, 2006). Véase la definición de 'transectos' [Rural-to-Urban Transect] dada por Bohl y Plater-Zybert: natural, rural, sub-urban, general urban, urban center y urban core. 
extendidas son las que emplean categorías morfológicas, tales como el casco antiguo, el ensanche, el bloque exento, la urbanización marginal, el polígono industrial, la vivienda unifamiliar, etc. Es preciso señalar que estas categorías son diferentes y albergan matices según continentes y países y según aspectos sociales, económicos, territoriales, etc. (Nelson, 1969; Solá-Morales, 1973; Griffin \& Ford, 1980; Johnson, 1994; Pinzón, 2009).

Con el trabajo seminal de Conzen (1960) se sentaron las bases de lo que hoy podemos denominar "categoría morfogenética o morfológica" a la hora de identificar formas urbanas a escala intraurbana. Conzen expuso que el crecimiento urbano y las formas internas que albergan las ciudades pueden capturarse a través de (a) los planes urbanísticos (town-plan) y la planta (ground plan) el cuál incorpora el emplazamiento, las calles, parcelas y manzanas-, (2) los edificios y (3) los usos y utilización del suelo y de los edificios (Conzen, 1960). Teniendo en cuenta lo anterior, señala que los patrones de calles, manzanas, parcelas y edificios, elementos físicos más duraderos o permanentes en el tiempo, da lugar a unidades morfológicas (plan unit) ${ }^{4}$, mientras que las actividades y funciones que alberga, aspectos menos duraderos o permanentes en el tiempo, da lugar a unidades de usos de suelo (units of land use).

En base a la categoría morfológica, Conzen (1975, 1988) propuso varias nociones: áreas homogéneas, regiones morfológicas o unidades de paisaje. Esta lectura ayuda a reconocer e identificar unas condiciones formales de unicidad propias de un tiempo y un espacio que son diferentes dentro de una misma ciudad ${ }^{5}$. La idea de categoría morfológica no trata a priori de plantear un estilo formal sino del reconocimiento de un de un espacio urbano conforme a unas exigencias socioeconómicas durante un periodo de tiempo. De este modo, las formas urbanas son leídas como un espacio proyectado que va más allá de examinar los elementos morfológicos de forma aislada o bidireccional sino en sus múltiples interrelaciones espaciales (Levy, 1999; Kropf, 2011).

A pesar de las sólidas bases del enfoque morfogenético este enfoque se ha visto complementado por tres aproximaciones (Moudon, 1997; Kropf, 2009, 2016; Oliveria, 2016): (a) la morfo-tipológica proveniente de la escuela italiana, (b) la relacional-material desde la escuela francesa y (c) la cuantitativa procedente del ámbito anglosajón-centro europeo (véase Figura 2).

4 El término 'plan unit' coincide con el término italiano 'tessuto' (Moudon, 1997; Kropf, 2009). Ambos identifican un grupo de edificios, espacios abiertos, parcelas y calles los cuales forman un conjunto coherente, o bien, porque ellos fueron construidos al mismo tiempo o dentro de las mismas limitaciones, o bien, porque ellos sufrieron un proceso común de transformación. Según Kropf (2009) el tejido urbano refiere al todo orgánico cuya forma puede ser descrita a diferentes niveles de resolución.

5 Para profundizar en este tema véase la noción de periodo morfológico propuesta por Conzen (1960) y desarrollada posteriormente (Whitehand, 1987; Whitehand et al., 2014) 


\section{Figura 2. Aproximaciones al estudio de la morfología o forma urbana}

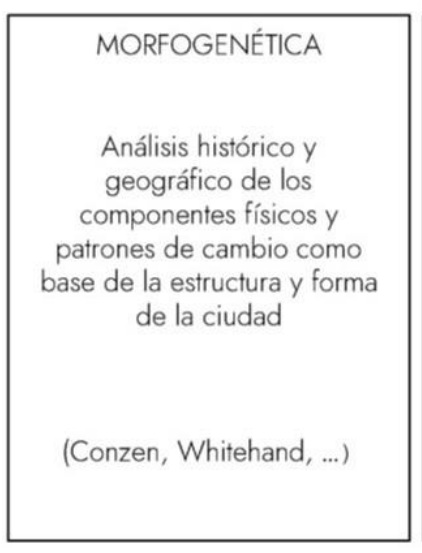

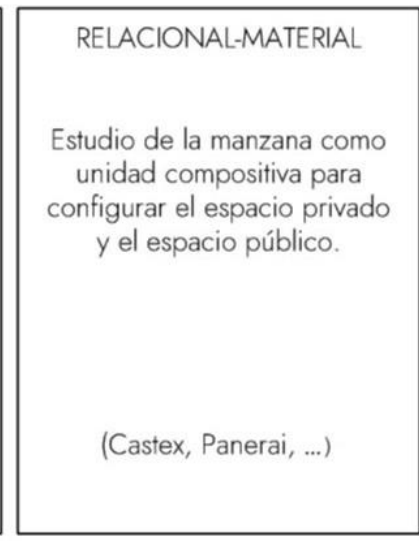

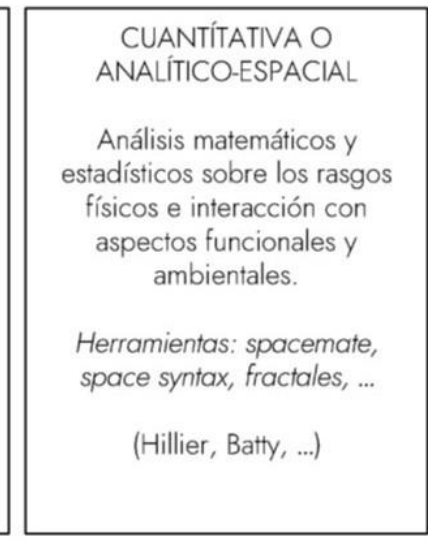

Fuente: elaboración propia

En este artículo planteamos complementar el enfoque morfogenético con el enfoque cuantitativo. Frente a los métodos tradicionales ligados al enfoque morfogenético, 6 las mejoras en los sistemas de información geográfica, el desarrollo en las tecnologías de la información y el incremento cualitativo y disponibilidad de datos georreferenciados, ha enriquecido el campo de investigación sobre forma urbana con nuevas herramientas y métodos cuantitativos (Tsai, 2005; Clifton et al., 2008; Pinho \& Oliveria, 2009; Ye \& van Ness, 2014). Esta situación ha llevado a reconocer una nueva aproximación en el estudio de las formas urbanas: la cuantitativa o analítico-espacial (Kropf, 2016; Oliveria, 2013, 2016). Si bien es cierto que este enfoque busca ser transversal y no busca sustituir otros enfoques, estamos ante un momento en el que se presta más atención a incorporar diversas herramientas y fuentes de información aplicada a diferentes casos, que a la elaboración de estudios críticos y comparativos entre estas herramientas, fuentes de información y casos. En este sentido, Schwarz (2010) Ilama la atención sobre la falta de métricas coherentes entre los diferentes estudios y la consiguiente limitación en nuestra capacidad para estudiar y comparar entornos urbanos entre ciudades, regiones o países.

Otro de los aportes recientes a los métodos morfogenéticos tiene que ver con la manera en que nos aproximamos o enfocamos el análisis cuantitativo de la forma urbana y su interrelación con la dinámica y funcionamiento de la ciudad. Según Clifton et al. (2008) y Nedovic-Budic et al. (2016) en los últimos años han aparecido cinco aproximaciones a este tema: ecología del paisaje (landscape ecology), estructura económica (economic structure), la planificación del transporte (transporting planning), diseño de comunidades (community design) y diseño urbano (urban design). Se trata de

6 Tradicionalmente el enfoque morfológico utilizando planos históricos para una misma ciudad había ido diferenciado diferentes partes o ámbitos al estilo conzeniano (estableciendo líneas de fijación, separando espacios con rasgos diferentes en la parcelación, ubicación del edificio, alturas, etc.), a ello se había superpuesto una lectura sobre las transformaciones efectuadas por agentes públicos y privados (Vilagrasa, 1998) y de los procesos en la manera en que se crece o se va construyendo la ciudad - parcelación, urbanización, edificación- (Solá-Morales, 1973). 
aproximaciones que nacen al calor de nuevos paradigmas - desarrollo urbano sostenible, del nuevo urbanismo, ciudad inteligente, etc. - y buscan dar respuesta a un nuevo modelo de ciudad. Con diferentes preocupaciones, orientaciones disciplinares, escalas y naturaleza de datos en sus análisis, la manera en que se mide, analiza y se entiende la forma urbana también es dispar (Dempsey et al., 2010). Esta situación pone de manifiesto, al menos, dos asuntos. De un lado, se evidencia que la complejidad de temas y métodos en torno al estudio de la forma urbana es consuetudinaria a la complejidad de los asentamientos humanos. De otro lado, muchos de los valores positivos -reducción del consumo de energía, mezcla de funciones, incremento del transporte público, vitalidad en calles, etc.- que encapsulan los nuevos paradigmas están conectados a la presencia de ciertas cualidades o condiciones espaciales (Collins \& Clarke, 1998; Burton, 2000; Jabareen, 2006; Gehl, 2006; Harper, 2013; Kyung \& Kain, 2016).

Sin embargo, a pesar de los avances en este enfoque cuantitativo, nos encontramos con la siguiente limitación: ¿cuál es el umbral que se establece como "deseable" o "aceptable" en relación con las condiciones o cualidades espaciales que debe tener la forma urbana? Es difícil establecer un dato "óptimo" a un hecho socioespacial. Dudamos que puedan establecerse parámetros universales de densidad, compacidad o cualquier otro tipo, ya que este escenario empobrecería la riqueza y diversidad cultural, histórica y de relaciones con el medio ambiente de cada territorio a lo largo de la historia. Sin embargo, no se renuncia a explorar cómo ciertas formas y propiedades espaciales aportan diferentes posibilidades para el dinamismo y vida urbano.

Teniendo en cuenta este contexto, nuestra contribución busca complementar el enfoque morfogenético desde la óptica cuantitativa a través de tres aspectos.

El primero, el uso de cartografía digital, fotografía aérea y el manejo de los Sistemas de Información Geográfica favorece la implementación del enfoque morfogenético a escala urbana. En el caso español, tras la revisión de la bibliografía sobre la clasificación de formas urbanas basada en la aproximación morfogenética (Solá-Morales, 1973, 1997; Capel, 1975; Moneo, 1982; López de Lucio, 1993; López de Lucio et al., 2016; Más, 1997, Zárate, 1998; de Santiago, 2006; RodríguezTarduchy, 2011) se ha creado la Figura 3, en la que se reconocen catorce formas urbanas o morfologías: casco antiguo, ensanche, vivienda unifamiliar, urbanización marginal, barraquismo, bloque exento -polígono de ordenación abierto-, polígonos industriales, espacios de oficina o ejes/áreas terciarias, espacios logísticos, nuevos ensanches, grandes equipamientos, grandes infraestructuras, centros comerciales y grandes operaciones de reforma en el tejido urbano existente. Mientras que estas formas urbanas pueden verse en las grandes ciudades y sus territorios metropolitanos, en ciudades de tamaño medio y asentamientos de menor tamaño, como consecuencia de su dinamismo, algunas de ellas no aparecen. El desarrollo de estas fuentes y herramientas, así como el reconocimiento de diferentes formas urbanas en el caso español, son aplicadas para el caso de Toledo (véanse apartados 3 y 4). 
El segundo, desde el enfoque cuantitativo se han seleccionado tres técnicas que permiten medir y comparar las propiedades espaciales de cada forma urbana: diagrama spacemate, diagrama $n$, modelo de mezcla de usos de suelo. No cabe duda de que el enfoque cuantitativo no es enteramente objetivo y hay que tomar partida por un conjunto de atributos y técnicas (Gil et al., 2012). En nuestro caso, estas técnicas permiten: (a) medir propiedades espaciales que resultan de la configuración de los componentes físicos de cada forma urbana; (b) establecer una comparativa entre estas propiedades y las formas resultantes; (c) interrelacionar aspectos físicos con aspectos funcionales.

Berhauser y Haup $(2005,2007,2010)$ impulsores de spacemate, señalan la importancia de tener una aproximación cuantitativa para clasificar diferentes tipos de formas urbanas $y$, disponer de un instrumento de control y marco para testar la planificación y la práctica del diseño. En consecuencia, diseñan las herramientas conocidas como gráfica spacemate y gráfica n (véanse Figura 4 y 5). 
Figura 3. Formas urbanas identificadas en las ciudades españolas desde el enfoque morfogenético

\begin{tabular}{|c|c|c|c|c|c|c|}
\hline $\begin{array}{c}\text { SOLÁ- } \\
\text { MORALES } \\
(1973,1997)\end{array}$ & $\begin{array}{cc}\text { CRECIMIENTO } \\
\text { SUBURBANO } \\
\text { ENSANCHE } \\
\text { (Exrarradio y } \\
\text { Núcleos } \\
\text { Adyacentes) }\end{array}$ & $\begin{array}{cc}\text { BARRIOS } & \text { BARRAQUISMO } \\
\text { CIUDADJARDIN } & \\
\text { (vivienda } & \text { URBANIZACIÓN } \\
\text { unifamiliar) } & \text { MARGINAL } \\
\end{array}$ & $\begin{array}{l}\text { POLIGONOS } \\
\text { RESIDENCIALES }\end{array}$ & s & 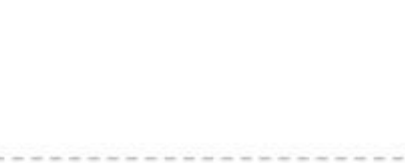 & 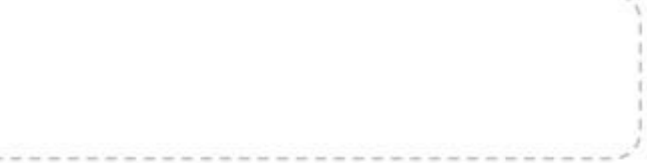 \\
\hline $\begin{array}{l}\text { CAPEL } \\
\text { (1975) }\end{array}$ & $\begin{array}{ll}\text { CASCO } & \text { NUCLEOS } \\
\text { ANTIGUO ENSANCHE } & \text { RURALES } \\
\text { INTEGRADOS }\end{array}$ & $\begin{array}{l}\text { BARRIOS DE } \\
\text { CIUDADIARDIN } \quad \text { SECTORES DE } \\
\text { (vivienda } \\
\begin{array}{c}\text { BARRAQUISMOY Y } \\
\text { unifamiliar) AUTOCONSTRUCCIOON }\end{array}\end{array}$ & $\begin{array}{l}\text { POLIGONOS } \\
\text { DE } \\
\text { N VIVIENDA }\end{array}$ & $\begin{array}{l}\text { SECTORES DE } \\
\text { URBANIZACIÓN } \\
\text { SECUNDARIA }\end{array}$ & & \\
\hline $\begin{array}{l}\text { MONEO } \\
\text { (1982) }\end{array}$ & & $\begin{array}{l}\text { BARRIOS } \\
\text { CIUDAD JARDIN } \\
\text { (vivienda } \\
\text { unifamiliar) }\end{array}$ & $\begin{array}{l}\text { POUGONOS } \\
\text { DE } \\
\text { VIVIENDA } \\
\text { RE: }\end{array}$ & $\begin{array}{l}\text { Periferia alejada y } \\
\text { zonas turísicas: } \\
\text { SEGUNDA AREAS } \\
\text { INDUSTRIALES } \\
\text { DE CIUDCAD a modo JARDIN }\end{array}$ & $\begin{array}{cc}\text { OPERACIONES } & \text { GRANDES } \\
\text { INFRA. } & \text { EDIFICIOS } \\
\text { ESTRUCTURALES } & \text { INSTITUCIONALES } \\
\text { VIARIAS DE GRAN } & \text { Y PRIVADOS } \\
\text { ESCALA } & \end{array}$ & \\
\hline $\begin{array}{l}\text { LOPEZ DE } \\
\text { LUCIO (1993, } \\
\text { 1999) }\end{array}$ & & $\begin{array}{l}\text { VIVIENDA } \\
\text { UNIFAMIIIAR } \\
\text { (periferias/suburbios) }\end{array}$ & $\begin{array}{l}\text { POLIGONOS } \\
\text { RESIDENCIALES }\end{array}$ & $\begin{array}{cc}\text { Periferia alejada: } & \text { POLGONOS } \\
\text { VIVENDA } & \text { NDUSTRIALES } \\
\text { UNIDAMILAR } & \text { EJES TERCIARIOS } \\
\text { BLOQUEE } & \text { OFCINAS- } \\
\text { RESIDENCIAL } & \text { LOGISTICOS }\end{array}$ & $\begin{array}{cc}\text { GRANDES INFRA. } & \text { GRANDES } \\
\text { ESTRUCTURAS } & \text { EQUIPAMIENTOS } \\
\text { DE TRANSPORTE } & \begin{array}{c}\text { (públicosy } \\
\text { privados) }\end{array} \\
& \end{array}$ & $\begin{array}{ccc}\text { NUEVOS } & \text { GRANDES } \\
\text { ENSANCHES COMERCIALES OPERACIONES } & \text { OPERACIONES } \\
& \text { MEFORMA EN } & \text { EL TEJDO } \\
& \text { MIXTAS } & \text { URBANO } \\
& \text { EXISTENTE }\end{array}$ \\
\hline $\begin{array}{l}\text { DE } \\
\text { SANTIAGO } \\
(2006)\end{array}$ & & & & & & $\begin{array}{l}\text { "GRANDES PIEZAS } \\
\text { URBANAS" } \\
\text { (pachtwork) * }\end{array}$ \\
\hline $\begin{array}{l}\text { RODRÍGUEZ } \\
\text { TARDUCHY } \\
\text { (2011) }\end{array}$ & $\begin{array}{l}\text { CASCO ENSANCHE } \\
\text { ANTIGUO ENS }\end{array}$ & $\begin{array}{l}\text { VIVIENDA } \\
\text { UNIFAMILIAR } \\
\text { (periferias/suburbios) }\end{array}$ & $\begin{array}{l}\text { BLOQUES } \\
\text { EXENTOS }\end{array}$ & $\begin{array}{c}\text { TEJIDOS } \\
\text { PRODUCTIVOS }\end{array}$ & & $\begin{array}{l}\text { NUEVOS } \\
\text { ENSANCHES }\end{array}$ \\
\hline
\end{tabular}

Fuente: elaboración propia 
La gráfica Spacemate aporta una lectura tridimensional de la densidad, informa sobre la interrelación entre ocupación, edificabilidad, amplitud y número de plantas (véase Figura 4). A partir de la gráfica spacemate puede identificarse un conjunto de grandes ámbitos urbanos ${ }^{7}$ (véase Figura 4). Si bien es cierto que esta técnica ha sido suficientemente probada (Berghauser \& Haup, 2009; Van Nes et al., 2012; Kickert et al., 2014; Steadman, 2014), como advierte García (2017, p. 164) "distintas formas urbanas pueden solaparse en el spacemate, dado que su rango de valores de densidad y compacidad son comunes", y añade que "la densidad y la compacidad al ser variables continuas, las transiciones entre unos tipos y otros son suaves, dificultando la delimitación precisa de tipos".

\section{Figura 4. Diagrama Spacemate}
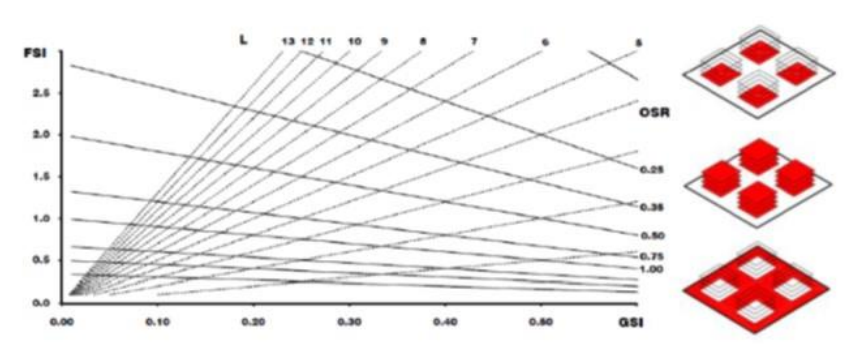

-GSI. Gross Space Index. Ocupación

Superficie del edifico en planta entre la superficie

del área total. Puede expresarse en tantos por uno o porcentaje.

-FSI. Floor Space Index. Coef. de Edificabilidad.

Superficie construida o edificada entre la superficie

del área total. Se expresa en $(\mathrm{m} 2 \mathrm{c} / \mathrm{m} 2 \mathrm{~s} ; \mathrm{m} 2 \mathrm{t} / \mathrm{m} 2 \mathrm{~s})$

-OSR. Open Space Ratio. Espaciosidad o Amplitud

Superficie de espacio no construido entre la superficie de espacio construido o edificado. Se expresa en $\mathrm{m} 2 / \mathrm{m} 2$.
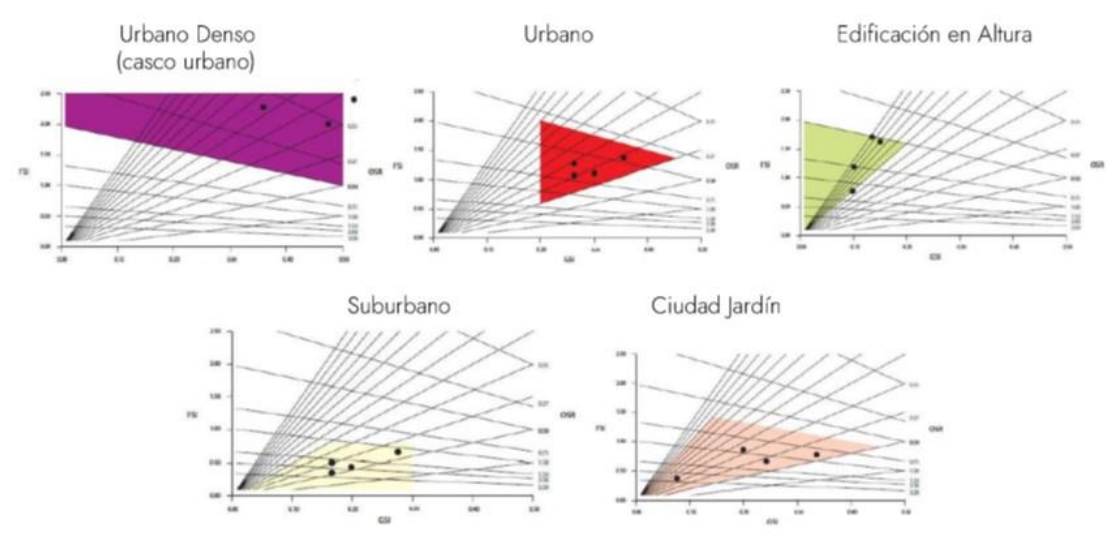

Fuente: Berghauser \& Haup (2010), reelaborado

El diagrama n nos informa sobre la relación existente entre cantidad de metros lineales de calle por metro cuadrado de superficie analizada (N), el ancho -promedio- de la calle (b) y la cantidad de metros cuadrados de espacio público por metro cuadrado de superficie analizada (T) (véase Figura 5). La gráfica n nos habla de las variaciones de la trama urbana en relación al tamaño de la manzana y sobredimensionamiento del espacio público.

7 Estos ámbitos urbanos están adaptados al caso de Ámsterdam. Podrían ser susceptibles de modificarse según contextos urbanos. 


\section{Figura 5. Diagrama $n$}
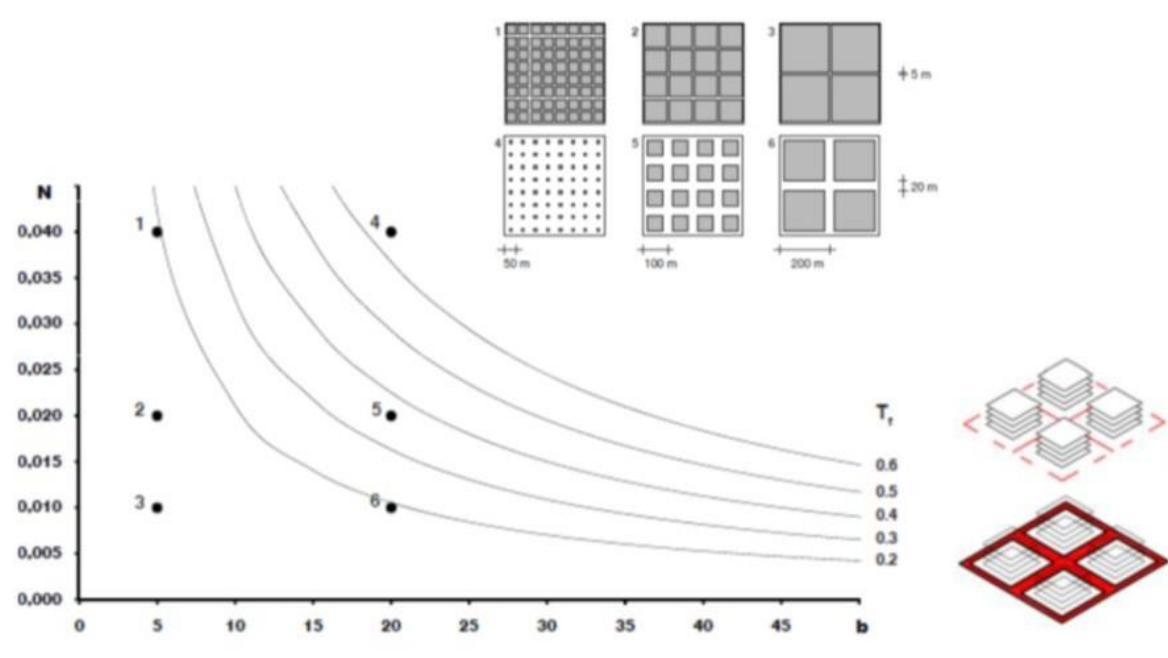

N. Density of Network. Densidad de viario.

$$
\begin{aligned}
& \mathrm{N}=\frac{\left(\sum \mathrm{l}_{1}+\frac{\left.\sum \mathrm{l}_{\mathrm{e}}\right)}{2}\right.}{\mathrm{A}} \\
& \text {-T. Tara. Relación entre la superficie de } \\
& \text { espacio público y la superficie de } \\
& \text { espacio privado. }
\end{aligned}
$$

-b. Profile width. Acho de calle.

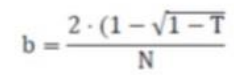

$\mathrm{Li}=$ longitud del viario interior Le $=$ longitud del viario exterior $A=$ superficie total del área

Fuente: Berghauser \& Haup (2010), reelaborado

El modelo de mezcla funcional mide el porcentaje de uso residencial, uso destinado al trabajo oficinas, industrias, comercios- y uso orientado a equipamientos en metros cuadrados en un área dada (Van den Hoek, 2008, 2009). Estos tres grupos de funciones son representados gráficamente en un diagrama con forma de triángulo equilátero. Las tres esquinas del triángulo corresponden con la superficie en planta de un uso respectivamente, que bien son $100 \%$ espacios destinados a uso residencial, $100 \%$ lugares de trabajo o $100 \%$ equipamientos (véase Figura 6). Van den Hoek (2008), para su estudio en Ámsterdam, desarrollo el índice de mezcla de usos que medía la ratio de funciones residenciales y no residenciales por superficie, para un conjunto de barrios con diferente grano, mezcla de uso y etapa histórica. Éste índice presenta un rango que va de 1 a 100 dependiendo del porcentaje total de suelo desarrollado para uso residencial. Van den Hoek encontró que en partes históricas de la ciudad la presencia residencial está 40 y el 60 \%, incrementándose al 70-85\% en áreas construidas a lo largo del siglo XIX y después alcanzando el 90 y el $95 \%$ en áreas del siglo XX. Van den Hoek argumenta que la proporción entre usos residenciales y no residenciales debería ser 50-50 con el objeto de crear urbanidad.

Si bien es cierto que el índice creado por van den Hoek tiene gran poder visual, no es muy útil para poder relacionar las propiedades espaciales con la presencia y mezcla de usos de suelo. Por ello, como contribución proponemos el uso del análisis estadístico factorial y del índice de complejidad urbana, obtenido mediante la aplicación del índice de Shannon-Weiner. Éste índice informa sobre la riqueza, información sobre el número de usos/funciones del suelo y la equitatividad, el grado en que los diferentes usos/funciones son similares en cuanto a abundancia. En urbanismo es índice también es conocido como "complejidad urbana" y se define: CU $=-\sum$ Pi x Log2 (Pi); 'n' es el número de tipos de actividad diferentes -riqueza de especies-; 'Pi' es la abundancia relativa de cada especie, la 
proporción de entidades de una especie o tipo de actividad con respecto al número total de actividades existentes; 'Log2(Pi)' es el logaritmo en base 2 sobre la abundancia relativa de cada especie. Las puntuaciones de entropía son iguales a uno cuando el uso de la tierra es mezclado o heterogéneo y cero cuando el uso de la tierra es homogéneo. Diferentes estudios han utilizado este índice para evaluar la complejidad urbana (López et al., 2016) en este artículo dicho índice se utiliza como variable dependiente de ciertas propiedades o rasgos espaciales de la forma urbana.

Figura 6. Modelo de mezcla del uso de suelo

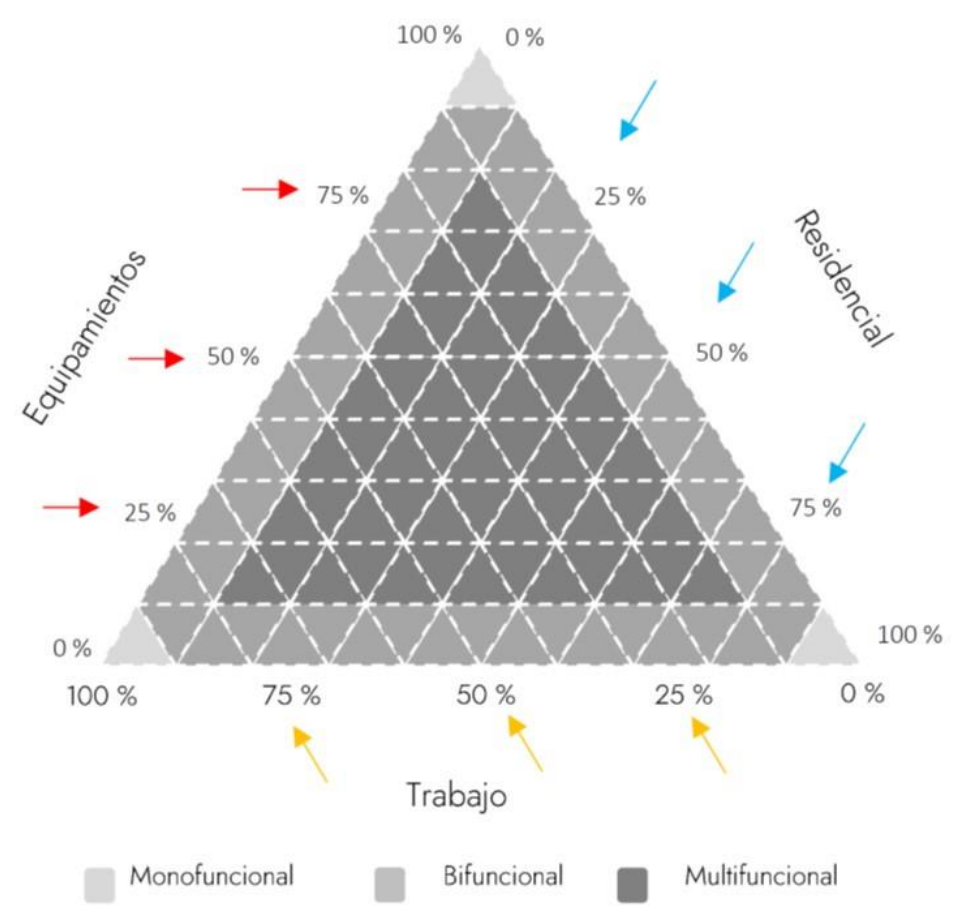

Fuente: Van de Hoek (2009), reelaborado

\section{Método y caso de estudio}

El método de trabajo para identificar y caracterizar las formas urbanas se articula en dos partes. La primera, a partir de la representación espacial de los elementos físicos del espacio público y privado y según el método morfogenético se identificarán las diferentes formas urbanas que caracterizan el caso de estudio propuesto, la ciudad de Toledo. En la segunda parte se efectúa una caracterización cuantitativa y comparación de las distintas formas urbanas, previamente identificadas, conforme a las técnicas: diagrama spacemate, diagrama n y diagrama del modelo de mezcla funcional. Posteriormente, a través de un análisis estadístico factorial e inferencial, se lleva cabo un estudio de la relación existente entre forma urbana y diversidad de usos.

\subsection{Reconocimiento e identificación de las formas urbanas}

El reconocimiento e identificación de las formas urbanas resulta de la combinación de la revisión de la bibliografía nacional sobre diferentes formas urbanas, una lectura de la realidad del municipio de 
Toledo en base a la fotografía aérea (Plan Nacional de Ortofotografía Aérea), la cartografía digital de catastro relativa a manzanas, parcelas y edificación, así como el trabajo de campo y el manejo de planes de ordenación urbana.

Entendiendo las formas urbanas como combinaciones o agregaciones más o menos repetidas de elementos físicos y de sus relaciones espaciales se han identificado una serie de ámbitos espaciales homogéneos o piezas de ciudad similares. A diferencia de otros estudios en los que el límite de las formas urbanas reconocidas se ajusta o circunscribe a un área de actuación homogénea -ya sea por ser una promoción unitaria pública, privada o mixta, etc. - sin que tenga necesariamente la misma superficie, aquí optamos por trabajar con una pieza de ciudad similar con una superficie uniforme de 25 ha. Cada una de estas partes de la ciudad se recoge en un cuadrado de 500 m de lado, cuya cara superior está orientada a norte. El hecho de analizar de manera homogénea la misma superficie para todas las formas tiene que ver con la idea que la producción y evolución del espacio urbano es complejo y consideramos que las piezas de ciudad que se analizan deben incluir todos aquellos aspectos que rodean o modifican las operaciones urbanas unitarias. Algunos de estos aspectos son naturales -ríos, topografía, espacios naturales, etc.- - otros humanos - legislación y normativas que regula la reserva de zonas verdes y equipamientos, cambios en el uso de suelo, derribo-obra nueva, etc - . Eso no significa que seamos conscientes de la pérdida de exactitud que supone trabajar con áreas que no son homogéneas como han señalado algunos autores (Berhauser \& Haup, 2010; García, 2017; Lopez de Lucio et al., 2016; Prieto et al., 2018).

\subsection{Caracterización cuantitativa de las formas urbanas}

En la Tabla 1 se presentan las variables e indicadores empleados en la caracterización cuantitativa de las formas urbanas identificadas. El cálculo es derivado de la información geométrica y alfanumérica procedente de catastro y el manejo del programa ArcMap 10.3.1/ArcCtatalog 10.3.1 y del programa Excel.

\section{Tabla 1. Variables e indicadores}

- Superficie de espacio público $\left(\mathrm{m}^{2}\right)$

- Superficie de espacio privado $\left(\mathrm{m}^{2}\right)$

- Superficie ocupada en planta por la edificación $\left(\mathrm{m}^{2}\right)$

- Superficie edificada o construida sobre rasante $\left(\mathrm{m}^{2} \mathrm{c}\right)$

- Superficie sin edificar pública y privada $\left(\mathrm{m}^{2}\right)$

- Superficie sin edificar pública $\left(\mathrm{m}^{2}\right)$

- Superficie sin edificar privada $\left(\mathrm{m}^{2}\right)$

- Número de viviendas

- Población (2,51 personas por hogar según datos del INE a fecha de 2018)

- Número de manzanas

- Número de parcelas

- Superficie de espacio peatonal en la red viaria $\left(\mathrm{m}^{2}\right)$

- Superficie de zonas verdes $\left(\mathrm{m}^{2}\right)$

- Superficie de espacio de circulación de vehículo y aparcamiento $\left(\mathrm{m}^{2}\right)$ 


\section{Tabla 1. Continuación}

- Número de intersecciones (encuentros de calles)

- Densidad ( $\mathrm{Hab} / \mathrm{Ha})$

- Espacio público (\% sobre el total)

- Espacio privado (\% sobre el total)

- Ocupación bruta (\%)

- Ocupación neta (\%)

- Edificabilidad bruta $\left(\mathrm{m}^{2} \mathrm{c} / \mathrm{m}^{2} \mathrm{~s}\right)$

- Edificabilidad neta $\left(\mathrm{m}^{2} \mathrm{c} / \mathrm{m} 2 \mathrm{~s}\right)$

- Tamaño medio de manzana $\left(\mathrm{m}^{2}\right)$

- Tamaño medio de parcelas $\left(\mathrm{m}^{2}\right)$

- Relación de parcelas por manzanas

- Espacio peatonal en la red viaria total (\%)

- Espacio peatonal sobre el total de superficie (\%)

- Espacio libre público (\%)

- Espacio libre privado (\%)

Gráfico spacemate

- Edificabilidad bruta $\left(\mathrm{m}^{2} \mathrm{c} / \mathrm{m}^{2} \mathrm{~s}\right)$

- Ocupación bruta (\%)

- Altura de la edificación (número de plantas)

- Amplitud o Espaciosidad $\left(\mathrm{m}^{2} / \mathrm{m}^{2}\right)$

Gráfico-Diagrama $n$

- Longitud de la red de calles (ml)

- Longitud de la red externa (ml)

- Tara (m2/m2)

- Densidad de la red de calles $(\mathrm{m} / \mathrm{m} 2)$

- Ancho de la calle (m)

- Malla (m)

Modelo de Mezcla Urbana Funcional

- Superficie de suelo residencial $\left(\mathrm{m}^{2}\right)$ - a

- Superficie de suelo destinado a comercio, oficina, industria, ocio y hostelería $\left(m^{2}\right)-b$

- Superficie de suelo destinado a equipamientos $\left(m^{2}\right)-b$

- Superficie total de usos $(a+b+c)-d$

- \% Uso de suelo residencial (a / d)

- \% Uso de suelo destinado a trabajo (b / d)

- \% Uso de suelo destinado a equipamientos (c / d)

- Índice de diversidad de Shannon-Weaver

Fuente: elaboración propia 
Tabla 2a. Variables e indicadores para cada forma urbana

\begin{tabular}{|c|c|c|c|c|c|c|c|c|c|c|c|c|c|c|c|c|}
\hline Formas urbanas & Ámbitos en Toledo & 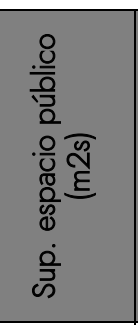 & 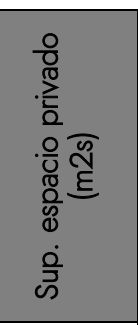 & 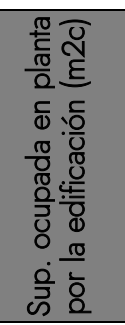 & 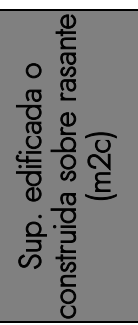 & 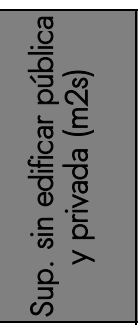 & 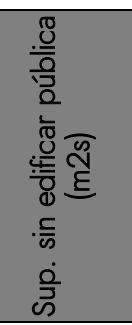 & 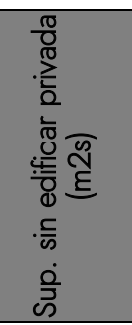 & 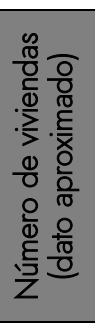 & 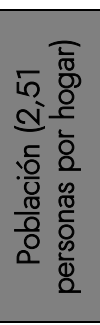 & 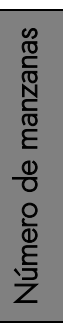 & $\begin{array}{l}\frac{1}{0} \\
\frac{\pi}{8} \\
\frac{0}{0} \\
\frac{0}{0} \\
0 \\
\frac{8}{0} \\
0 \\
\frac{0}{0} \\
\frac{E}{5} \\
\frac{5}{Z}\end{array}$ & 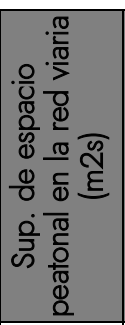 & 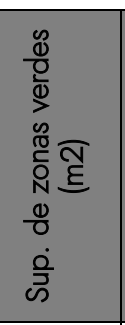 & 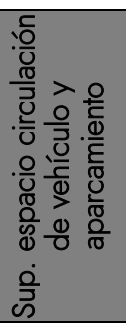 & 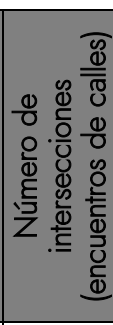 \\
\hline \multirow{2}{*}{ Casco Antiguo } & $\begin{array}{c}\text { Centro Histórico } \\
\text { (espacio intramuros) }\end{array}$ & 53150 & 196850 & 167787 & 635304 & 82213 & 53150 & 29063 & 2869 & 7201 & 73 & 809 & 53150 & 0 & 53150 & 120 \\
\hline & $\begin{array}{c}\text { Arrabal Covachuelas- } \\
\text { Antequeruela }\end{array}$ & 118172 & 131828 & 71245 & 218168 & 178328 & 118172 & 60156 & 1517 & 3808 & 66 & 504 & 43993 & 13387 & 60792 & 69 \\
\hline \multirow{2}{*}{$\begin{array}{c}\text { Urbanización } \\
\text { Marginal }\end{array}$} & Carretera de Madrid & 120505 & 129495 & 75396 & 331112 & 174604 & 120505 & 54099 & 1745 & 4380 & 52 & 193 & 44634 & 17826 & 58045 & 39 \\
\hline & Santa Bárbara & 108860 & 141140 & 52458 & 183759 & 197542 & 108860 & 88682 & 1541 & 3868 & 32 & 326 & 15499 & 41127 & 52234 & 29 \\
\hline \multirow{4}{*}{ Bloque Exento } & Reconquista & 124637 & 125363 & 45624 & 249389 & 204376 & 124637 & 79739 & 1273 & 3195 & 32 & 54 & 34302 & 64482 & 25853 & 42 \\
\hline & Palomarejos-Corea & 160880 & 89120 & 58120 & 266924 & 191880 & 160880 & 31000 & 1537 & 3858 & 52 & 199 & 31253 & 44689 & 84938 & 60 \\
\hline & Buenavista & 62913 & 187087 & 58151 & 399659 & 191849 & 62913 & 128936 & 1707 & 4285 & 10 & 47 & 19267 & 31878 & 11768 & 10 \\
\hline & $\begin{array}{c}\text { Polígono de Sta. } M^{a} \\
\text { Benquerencia }\end{array}$ & 117856 & 132144 & 51439 & 205193 & 198561 & 117856 & 80705 & 1743 & 4375 & 23 & 54 & 29291 & 40700 & 47865 & 31 \\
\hline \multirow{3}{*}{$\begin{array}{l}\text { Vivienda } \\
\text { Unifamiliar }\end{array}$} & Poblado Obrero & 57574 & 192426 & 30385 & 89885 & 219615 & 57574 & 162041 & 421 & 1057 & 23 & 183 & 9909 & 5937 & 41728 & 28 \\
\hline & Vistahermosa & 54850 & 195150 & 19491 & 32547 & 230509 & 54850 & 175659 & 115 & 289 & 9 & 72 & 6479 & 11644 & 36727 & 10 \\
\hline & Valparaíso & 87044 & 162956 & 40923 & 93668 & 209077 & 87044 & 122033 & 942 & 2364 & 26 & 128 & 14394 & 39275 & 33375 & 22 \\
\hline \multirow{2}{*}{ Nuevo Ensanche } & $\begin{array}{c}\text { Polígono de Sta. } M^{2} \\
\text { Benquerencia }\end{array}$ & 130945 & 119055 & 39262 & 207221 & 210738 & 130945 & 79793 & 1468 & 3685 & 37 & 71 & 45394 & 20490 & 65061 & 14 \\
\hline & Avenida de Europa & 89939 & 160061 & 59236 & 246093 & 190764 & 89939 & 100825 & 1070 & 2686 & 17 & 64 & 10611 & 29732 & 49596 & 24 \\
\hline $\begin{array}{c}\text { Centros } \\
\text { Comerciales } \\
\end{array}$ & Luz del Tajo & 129829 & 120171 & 28246 & 131655 & 221754 & 129829 & 91925 & 0 & 0 & 3 & 6 & 5523 & 61070 & 63236 & 4 \\
\hline $\begin{array}{c}\text { Grandes Espacios } \\
\text { de Oficina }\end{array}$ & $\begin{array}{c}\text { Polígono de Sta. } M^{2} \\
\text { Benquerencia }\end{array}$ & 121431 & 128569 & 40478 & 120072 & 209522 & 121431 & 88091 & 337 & 846 & 13 & 17 & 38056 & 16816 & 66559 & 11 \\
\hline \multirow{2}{*}{$\begin{array}{l}\text { Espacios } \\
\text { Industriales }\end{array}$} & $\begin{array}{c}\text { Polígono de Sta. } M^{2} \\
\text { Benquerencia-l }\end{array}$ & 117781 & 132219 & 72493 & 93470 & 177507 & 117781 & 59726 & 0 & 0 & 5 & 40 & 10362 & 24992 & 82427 & 6 \\
\hline & $\begin{array}{c}\text { Polígono de Sta. } M^{2} \\
\text { Benquerencia-ll }\end{array}$ & 45322 & 204678 & 113193 & 206915 & 136807 & 45322 & 91485 & 0 & 0 & 8 & 108 & 7513 & 0 & 37809 & 2 \\
\hline $\begin{array}{c}\text { Grandes } \\
\text { Equipamientos }\end{array}$ & $\begin{array}{c}\text { IES Universidad } \\
\text { Laboral }\end{array}$ & 50753 & 199247 & 49453 & 218466 & 200547 & 50753 & 149794 & 206 & 517 & 11 & 30 & 11733 & 19603 & 19417 & 6 \\
\hline \multirow[b]{2}{*}{ Espacio Mixto } & Valparaíso & 64552 & 185448 & 47036 & 117293 & 202.964 & 64552 & 138412 & 1574 & 3951 & 17 & 242 & 20507 & 4015 & 40030 & 20 \\
\hline & $\begin{array}{c}\text { Polígono de Sta } M^{a} \\
\text { Benquerencia }\end{array}$ & 141594 & 108406 & 44560 & 174006 & 205.440 & 141594 & 63846 & 721 & 1810 & 24 & 119 & 29535 & 51471 & 60588 & 12 \\
\hline
\end{tabular}

Fuente: elaboración propia 
Tabla 2b. Variables e indicadores para cada forma urbana

\begin{tabular}{|c|c|c|c|c|c|c|c|c|c|c|c|c|c|c|c|c|}
\hline Formas urbanas & Ámbitos en Toledo & 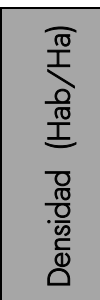 & 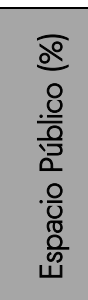 & 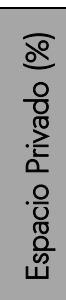 & 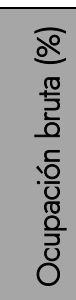 & 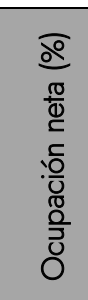 & 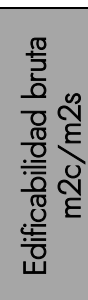 & 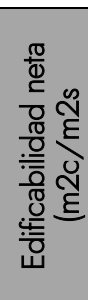 & 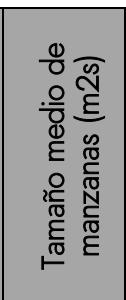 & 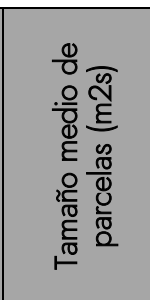 & 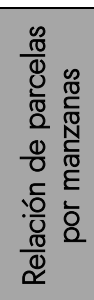 & 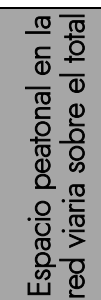 & 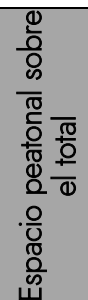 & 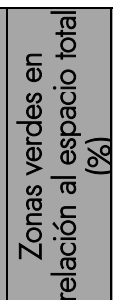 & 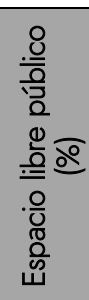 & 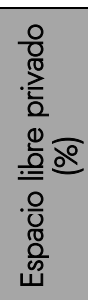 \\
\hline \multirow{2}{*}{ Casco Antiguo } & Centro Histórico (espacio intramuros) & 288,0 & 21,3 & 79 & 67,1 & 85,2 & 2,5 & 3 & 2697 & 243,3 & 11,1 & 100,0 & 21,3 & 0,0 & 21,3 & 12 \\
\hline & Arrabal Covachuelas-Antequeruela & 152,3 & 47,3 & 53 & 28,5 & 54,0 & 0,9 & 2 & 1997 & 261,6 & 7,6 & 37,2 & 17,6 & 11,3 & 47,3 & 24 \\
\hline \multirow{2}{*}{ Urbanización Marginal } & Carretera de Madrid & 175,2 & 48,2 & 52 & 30,2 & 58,2 & 1,3 & 3 & 2.490 & 671,0 & 3,7 & 37,0 & 17,9 & 14,8 & 48,2 & 22 \\
\hline & Santa Bárbara & 154,7 & 43,5 & 56 & 21,0 & 37,2 & 0,7 & 1 & 4411 & 432,9 & 10,2 & 14,2 & 6,2 & 37,8 & 43,5 & 35 \\
\hline \multirow{4}{*}{ Bloque Exento } & Reconquista & 127,8 & 49,9 & 50 & 18,2 & 36,4 & 1,0 & 2 & 3.918 & 2321,5 & 1,7 & 27,5 & 13,7 & 51,7 & 49,9 & 32 \\
\hline & Palomajeros-Corea & 154,3 & 64,4 & 36 & 23,2 & 65,2 & 1,1 & 3 & 1714 & 447,8 & 3,8 & 19,4 & 12,5 & 27,8 & 64,4 & 12 \\
\hline & Buenavista & 171,4 & 25,2 & 75 & 23,3 & 31,1 & 1,6 & 2 & 18.709 & 3980,6 & 4,7 & 30,6 & 7,7 & 50,7 & 25,2 & 52 \\
\hline & Polígono de Sta. $M^{a}$ Benquerencia & 175,0 & 47,1 & 53 & 20,6 & 38,9 & 0,8 & 2 & 5745 & 2447,1 & 2,3 & 24,9 & 11,7 & 34,5 & 47,1 & 32 \\
\hline \multirow{3}{*}{ Vivienda Unifamiliar } & Poblado Obrero & 42,3 & 23,0 & 77 & 12,2 & 15,8 & 0,4 & 0 & 8366 & 1051,5 & 8,0 & 17,2 & 4,0 & 10,3 & 23,0 & 65 \\
\hline & Vistahermosa & 11,5 & 21,9 & 78 & 7,8 & 10,0 & 0,1 & 0 & 21683 & 2710,4 & 8,0 & 11,8 & 2,6 & 21,2 & 21,9 & 70 \\
\hline & Valparaíso & 94,6 & 34,8 & 65 & 16,4 & 25,1 & 0,4 & 1 & 6268 & 1273,1 & 4,9 & 16,5 & 5,8 & 45,1 & 34,8 & 49 \\
\hline \multirow{2}{*}{ Nuevo Ensanche } & Polígono de Sta. $M^{a}$ Benquerencia & 147,4 & 52,4 & 48 & 15,7 & 33,0 & 0,8 & 2 & 3218 & 1676,8 & 1,9 & 34,7 & 18,2 & 15,6 & 52,4 & 32 \\
\hline & Avenida de Europa & 107,4 & 36,0 & 64 & 23,7 & 37,0 & 1,0 & 2 & 9415 & 2501,0 & 3,8 & 11,8 & 4,2 & 33,1 & 36,0 & 40 \\
\hline Centros Comerciales & Luz del Tajo & 0,0 & 51,9 & 48 & 11,3 & 23,5 & 0,5 & 1 & 40057 & 20028,5 & 2,0 & 4,3 & 2,2 & 47,0 & 51,9 & 37 \\
\hline $\begin{array}{l}\text { Grandes Espacios de } \\
\text { Oficina }\end{array}$ & Polígono de Sta. M Benquerencia & 33,8 & 48,6 & 51 & 16,2 & 31,5 & 0,5 & 1 & 9890 & 7562,9 & 1,3 & 31,3 & 15,2 & 13,8 & 48,6 & 35 \\
\hline \multirow{2}{*}{ Espacios Industriales } & Polígono de Sta. Mª Benquerencia-l & 0,0 & 47,1 & 53 & 29,0 & 54,8 & 0,4 & 1 & 26444 & 3305,5 & 8,0 & 8,8 & 4,1 & 21,2 & 47,1 & 24 \\
\hline & Polígono de Sta. Maªnquerencia-ll & 0,0 & 18,1 & 82 & 45,3 & 55,3 & 0,8 & 1 & 25585 & 1895,2 & 13,5 & 16,6 & 3,0 & 0,0 & 18,1 & 37 \\
\hline Grandes Equipamientos & IES Universidad Laboral & 20,7 & 20,3 & 80 & 19,8 & 24,8 & 0,9 & 1 & 18113 & 6641,6 & 2,7 & 23,1 & 4,7 & 38,6 & 20,3 & 60 \\
\hline \multirow{2}{*}{ Espacio Mixto } & Valparaíso & 158,0 & 25,8 & 74 & 18,8 & 25,4 & 0,5 & 1 & 10909 & 766,3 & 14,2 & 31,8 & 8,2 & 6,2 & 25,8 & 55 \\
\hline & Polígono de Sta M Menquerencia & 72,4 & 56,6 & 43 & 17,8 & 41,1 & 0,7 & 2 & 4517 & 911,0 & 5,0 & 20,9 & 11,8 & 36,4 & 56,6 & 26 \\
\hline
\end{tabular}

Fuente: elaboración propia 
Tabla 2c. Variables e indicadores para cada forma urbana

\begin{tabular}{|c|c|c|c|c|c|c|c|c|c|c|c|c|c|c|c|c|c|c|c|}
\hline \multirow[b]{2}{*}{ Formas Urbanas } & \multirow[b]{2}{*}{ Ámbitos en Toledo } & \multicolumn{4}{|c|}{ Gráfico Spacemate } & \multicolumn{6}{|c|}{ Gráfico Diagrama N } & \multicolumn{8}{|c|}{ Modelo de Mezcla Funcional (MMF) } \\
\hline & & 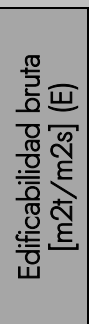 & $\begin{array}{l}\overline{0} \\
\overline{0} \\
\frac{0}{0} \\
\frac{0}{5} \\
\frac{0}{0} \\
\frac{1}{0} \\
\frac{0}{0} \\
\frac{0}{3} \\
\frac{0}{0} \\
0\end{array}$ & 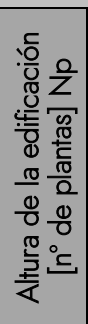 & 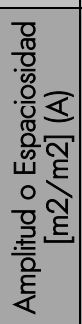 & 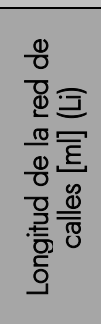 & 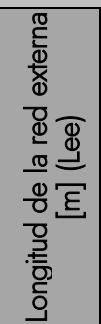 & 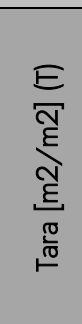 & 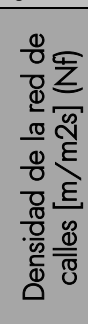 & 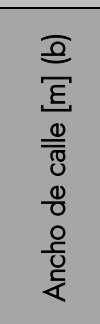 & $\begin{array}{l}\bar{z} \\
\underline{E} \\
\frac{\pi}{\overline{N 0}}\end{array}$ & 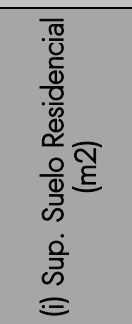 & 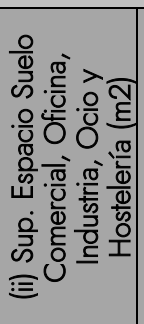 & 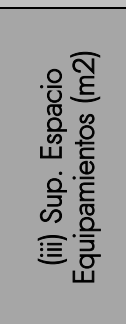 & 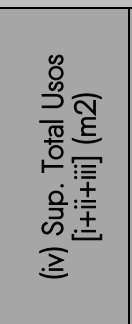 & 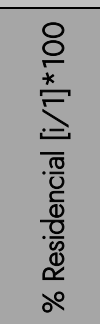 & 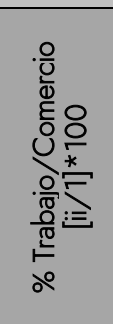 & 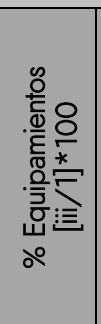 & 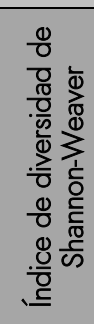 \\
\hline \multirow{2}{*}{ Casco Antiguo } & $\begin{array}{c}\text { Centro Histórico (espacio } \\
\text { intramuros) }\end{array}$ & 2,5 & 67,1 & 3,8 & 0,1 & 7968 & 2000 & 0,21 & 0,04 & 6,28 & 3,14 & 323692 & 135187 & 109353 & 568232 & 56,96 & 23,79 & 19,24 & 0,788 \\
\hline & $\begin{array}{c}\text { Arrabal Covachuelas- } \\
\text { Antequeruela }\end{array}$ & 0,9 & 28,5 & 3,1 & 0,8 & 7625 & 2000 & 0,47 & 0,03 & 15,87 & 7,94 & 132420 & 42769 & 55964 & 231153 & 57,29 & 18,50 & 24,21 & 0,435 \\
\hline \multirow{2}{*}{$\begin{array}{l}\text { Urbanización } \\
\text { Marginal }\end{array}$} & Carretera de Madrid & 1,3 & 30,2 & 4,4 & 0,5 & 5673 & 2000 & 0,48 & 0,03 & 21,00 & 10,50 & 178792 & 107627 & 35925 & 322344 & 55,47 & 33,39 & 11,14 & 0,541 \\
\hline & Santa Bárbara & 0,7 & 21,0 & 3,5 & 1,1 & 4046 & 2000 & 0,44 & 0,02 & 24,64 & 12,32 & 150209 & 18066 & 9931 & 178206 & 84,29 & 10,14 & 5,57 & 0,318 \\
\hline \multirow{4}{*}{ Bloque Exento } & Reconquista & 1,0 & 18,2 & 5,5 & 0,8 & 4887 & 2000 & 0,50 & 0,02 & 24,79 & 12,39 & 170995 & 61620 & 31511 & 264126 & 64,74 & 23,33 & 11,93 & 0,463 \\
\hline & Palomarejos - Corea & 1,1 & 23,2 & 4,6 & 0,7 & 6843 & 2000 & 0,64 & 0,03 & 25,69 & 12,84 & 163775 & 32997 & 96992 & 293764 & 55,75 & 11,23 & 33,02 & 0,508 \\
\hline & Buenavista & 1,6 & 23,3 & 6,9 & 0,5 & 2261 & 2000 & 0,25 & 0,01 & 20,69 & 10,34 & 300805 & 41382 & 23076 & 365263 & 82,35 & 11,33 & 6,32 & 0,515 \\
\hline & $\begin{array}{l}\text { Polígono de Sta. } M^{a} \\
\text { Benquerencia }\end{array}$ & 0,8 & 20,6 & 4,0 & 1,0 & 4553 & 2000 & 0,47 & 0,02 & 24,58 & 12,29 & 169568 & 25700 & 11203 & 206471 & 82,13 & 12,45 & 5,43 & 0,356 \\
\hline \multirow{3}{*}{ Vivienda Unifamiliar } & Poblado Obrero & 0,4 & 12,2 & 3,0 & 2,4 & 4113 & 2000 & 0,23 & 0,02 & 12,00 & 6,00 & 65829 & 6761 & 26489 & 99079 & 66,44 & 6,82 & 26,74 & 0,224 \\
\hline & Vistahermosa & 0,1 & 7,8 & 1,7 & 7,1 & 2967 & 2000 & 0,22 & 0,02 & 14,68 & 7,34 & 28876 & 100 & 3696 & 32672 & 88,38 & 0,31 & 11,31 & 0,086 \\
\hline & Valparaíso & 0,4 & 16,4 & 2,3 & 2,2 & 5045 & 2000 & 0,35 & 0,02 & 15,93 & 7,97 & 94261 & 516 & 7535 & 102312 & 92,13 & 0,50 & 7,36 & 0,200 \\
\hline \multirow{2}{*}{ Nuevo Ensanche } & $\begin{array}{c}\text { Polígono de Sta. } M^{a} \\
\text { Benquerencia }\end{array}$ & 0,8 & 15,7 & 5,3 & 1,0 & 3988 & 2000 & 0,52 & 0,02 & 31,07 & 15,53 & 146605 & 13662 & 29029 & 189296 & 77,45 & 7,22 & 15,34 & 0,346 \\
\hline & Avenida de Europa & 1,0 & 23,7 & 4,2 & 0,8 & 3262 & 2000 & 0,36 & 0,02 & 23,45 & 11,72 & 197741 & 62475 & 14126 & 274342 & 72,08 & 22,77 & 5,15 & 0,452 \\
\hline Centro Comercial & Luz del Tajo & 0,5 & 11,3 & 4,7 & 1,7 & 2025 & 2000 & 0,52 & 0,01 & 50,69 & 25,35 & 0 & 0 & 66019 & 66019 & 0,00 & 0,00 & $\begin{array}{c}100,0 \\
0\end{array}$ & 0,134 \\
\hline $\begin{array}{l}\text { Grandes Espacios } \\
\text { de Oficina }\end{array}$ & $\begin{array}{l}\text { Polígono de Sta. } M^{a} \\
\text { Benquerencia }\end{array}$ & 0,5 & 16,2 & 3,0 & 1,7 & 2904 & 2000 & 0,49 & 0,02 & 36,23 & 18,11 & 49444 & 40059 & 40376 & 129879 & 38,07 & 30,84 & 31,09 & 0,294 \\
\hline \multirow{2}{*}{$\begin{array}{l}\text { Espacios } \\
\text { Industriales }\end{array}$} & $\begin{array}{c}\text { Polígono de Sta. } M^{2} \\
\text { Benquerencia-l }\end{array}$ & 0,4 & 29,0 & 1,3 & 1,9 & 1655 & 2000 & 0,47 & 0,01 & 51,37 & 25,68 & 3659 & 80679 & 0 & 84338 & 4,34 & 95,66 & 0,00 & 0,169 \\
\hline & $\begin{array}{c}\text { Polígono de Sta. } M^{2} \\
\text { Benquerencia-ll }\end{array}$ & 0,8 & 45,3 & 1,8 & 0,7 & 1658 & 2000 & 0,18 & 0,01 & 17,90 & 8,95 & 0 & 174880 & 0 & 174880 & 0,00 & 100,00 & 0,00 & 0,262 \\
\hline $\begin{array}{l}\text { Grandes } \\
\text { Equipamientos }\end{array}$ & IES Universidad Laboral & 0,9 & 19,8 & 4,4 & 0,9 & 1716 & 2000 & 0,20 & 0,01 & 19,75 & 9,87 & 138182 & 35772 & 76888 & 250842 & 55,09 & 14,26 & 30,65 & 0,460 \\
\hline \multirow[b]{2}{*}{ Espacios Mixtos } & Valparaíso & 0,5 & 18,8 & 2,5 & 1,7 & 3872 & 2000 & 0,26 & 0,02 & 14,24 & 7,12 & 106294 & 5784 & 5961 & 118039 & 90,05 & 4,90 & 5,05 & 0,228 \\
\hline & $\begin{array}{c}\text { Polígono de Sta } \mathrm{M}^{a} \\
\text { Benquerencia }\end{array}$ & 0,7 & 17,8 & 3,9 & 1,2 & 3511 & 2000 & 0,57 & 0,02 & 37,85 & 18,93 & 182481 & 14845 & 1028 & 198354 & 92,00 & 7,48 & 0,52 & 0,316 \\
\hline
\end{tabular}

Fuente: elaboración propia 
En la Tabla 2c se muestran los datos utilizados para el cálculo de las herramientas spacemate, diagrmama n y diagrama del modelo de mezcla urbana funcional. Los datos de uso del suelo se obtienen de la información que ofrece Catastro por parcela. A pesar de que la codificación de usos que ofrece Catastro está condicionada por su finalidad fiscal y el control de la propiedad (Velasco, 2007), dicha fuente se considera fiable y robusta para el objetivo que persigue este artículo. En base a la agrupación de usos que establece van de Hoek $(2008,2009)$ para el diagrama de mezcla urbana funcional, en la Tabla 3 hemos reclasificado los usos de catastro.

Tabla 3. Codificación de los usos de los bienes inmuebles de Catastro.

Reclasificación para el estudio del índice de mezcla de uso de suelo

\begin{tabular}{|c|c|c|c|c|}
\hline \multirow[b]{2}{*}{ Código } & \multirow[b]{2}{*}{ Uso } & \multicolumn{3}{|c|}{ Reclasificación } \\
\hline & & $\begin{array}{l}\text { Uso } \\
\text { Residencial }\end{array}$ & $\begin{array}{l}\text { Uso relativo a } \\
\text { actividades } \\
\text { económicas }\end{array}$ & $\begin{array}{l}\text { Uso de } \\
\text { Equipamiento }\end{array}$ \\
\hline A & Almacén-Estacionamiento & & & \\
\hline $\mathrm{V}$ & Residencial & $X$ & & \\
\hline 1 & Industrial & & $X$ & \\
\hline $\mathrm{O}$ & Oficinas & & $\mathrm{X}$ & \\
\hline C & Comercial & & $X$ & \\
\hline $\mathrm{K}$ & Deportivo & & & $X$ \\
\hline$T$ & Espectáculos & & & $X$ \\
\hline G & Ocio y Hostelería & & $X$ & \\
\hline $\mathrm{Y}$ & Sanidad y Beneficencia & & & $X$ \\
\hline $\mathrm{E}$ & Cultural & & & $\mathrm{X}$ \\
\hline $\mathrm{R}$ & Religioso & & & \\
\hline M & $\begin{array}{l}\text { Obras de urbanización y jardinería, } \\
\text { suelos si edificar }\end{array}$ & & & \\
\hline$P$ & Edificio Singular & & & \\
\hline $\mathrm{B}$ & Almacén agrario & & & \\
\hline I & Industrial agrario & & & \\
\hline Z & Agrario & & & \\
\hline
\end{tabular}

Fuente: elaboración propia

\subsection{Relación entre forma urbana y mezcla de usos}

Para conocer la relación entre forma urbana y mezcla de usos se empelará el análisis estadístico factorial e inferencial. En los últimos años, estos análisis han sido incorporado a estudios sobre forma urbana (Clifton et al., 2008; Schward, 2010). El análisis factorial es una técnica estadística, enmarcada dentro de los métodos multivariantes, que persigue una doble finalidad. Por un lado, reduce las dimensiones del problema -estudiando las correlaciones existentes entre las variables observadas construye un número menor de variables ficticias llamadas factores que resumen la información-. Por otro lado, identifica estructuras internas en los datos, en el sentido de descubrir agrupaciones de variables que explican un mismo constructo. En definitiva, el análisis factorial permite seleccionar aquellas variables con mayor poder explicativo -excluyendo aquellas que redundan 
información- y para la agrupación de variables que entre ellas identifiquen una misma idea, denominadas componentes y denotados como la letra " $\mathrm{C}$ ".

Así de las 29 variables -excluidas las variables relativas al uso del suelo- con las que se trabajan para la caracterización de las formas urbanas (véanse Tablas 2a y 2b), el análisis de correlaciones realizado en SPSS permite quitar variables redundantes y establecer un total de 17 variables (véase Figura 12). A continuación, a través del análisis factorial, se seleccionan grupos de variables propiedades espaciales- que explican un mismo constructo o componente. A través de estas componentes se valora la influencia de las propiedades espaciales con la mezcla de usos del suelo.

\subsection{Caso de estudio}

Este trabajo ofrece un carácter complementario a otros estudios que desde la aproximación morfológica han analizado el caso de Toledo. Tras la revisión de estos estudios podemos diferenciar aquellos centrados en (a) la evolución del plano y del planeamiento (Terán, 1951; García-Pablos, 1964; Torres, 1970; Porres, 1989; Muelas \& Parrila, 2007; Ahedo, 2018); (b) en las calles y sus cambios morfológicos y funcionales (Porres, 1971; Del Cerro, 1995; Ruiz-Apilánez, Arnáiz \& Ureña, 2015); (c) en la tipología edificatoria (Navascúes, 1983; Passini, 1994; Busquets, 2000; Santacruz, 2016); (d) en el casco histórico y sus trasformaciones físicas, sociales y funcionales (Zárate \& Vazquez, 1983; Campos et al., 1988; Busquets, 2000) y, (e) en los agentes urbanos, procesos de difusión y formas de crecimiento de la ciudad (Moraleda \& Peces, 1991; Zárate, 1998; Benito, 1998; Ureña, 2012; Escudero, 2018a, 2018b). A diferencia de estos estudios el presente trabajo aporta como novedad la combinación del método morfogenético y cuantitativo. Por un lado, el enfoque morfogenético apoyado en la configuración espacial de los componentes físicos del espacio público y privado permite identificar diferentes formas urbanas. Por otro lado, el enfoque cuantitativo sirve para medir y comparar las propiedades físicas de dichas formas, así como para evaluar su influencia en la mezcla de usos del suelo.

A lo anterior se añaden dos motivos más por los que se toma Toledo como laboratorio de estudio. El primero, Toledo es una ciudad de tamaño medio que, además de su condición de centralidad histórica, es un potente nodo turístico internacional, un centro económico de la región urbana madrileña y capital político-administrativa de la Comunidad de Castilla-La Mancha (Solís et al., 2012; Solís et al., 2018). Estos rasgos han ido transformando la ciudad de Toledo en las últimas décadas, cuestión por la que adquiere importancia conocer las formas urbanas que están produciendo y sustentan dichos cambios. El segundo, reconociendo que las formas urbanas acaban definiendo la estructura funcional, la articulación y el paisaje de la ciudad en su conjunto, el conocimiento de las formas urbanas puede ser una vía para orientar y acompasar el tradicional desajuste que sufre la ciudad de Toledo entre los diferentes espacios urbanos que constituyen la ciudad y entre el desenvolvimiento socioeconómico, su planificación urbana y el planeamiento urbanístico. 


\section{Resultados}

\subsection{Identificación de las formas urbanas para el caso de Toledo}

Según el método morfogenético se han identificado 10 formas urbanas. Ahora bien, para algunas de estas se presentan diferentes ejemplos como consecuencia de variantes. Por ejemplo, en el caso de la vivienda unifamiliar distinguimos entre el caso del "Poblado Obrero", de "Cigarrales de Vistahermosa" y de "Valparaíso". La diferencia radica en que respondiendo todas a un modelo de ocupación de baja densidad, una vivienda por parcela, presentan cambios y/o variantes en el tamaño de manzana, parcela, tipo de edificación -aislada, pareada, hilera- así como en la configuración del espacio público -anchura de las calles, tamaño de las plazas y zonas verdes, por ejemplo-. En la Figura 7 se detallan todos los casos estudiados y en la Figura 8 se localizan sobre la fotografía área.

La ciudad de Toledo recoge una gran variedad de formas urbanas. Ello se debe al dinamismo de la ciudad y su condición de centralidad territorial histórica y actual. La mayor parte de estas morfologías se han constituido en la segunda mitad del siglo XX, por tanto, forman parte del paisaje urbano contemporáneo. Las formas urbanas descritas ofrecen una nueva mirada a la tradicional lectura de la ciudad de Toledo. Toledo, además de responder a un modelo disperso, formado por piezas que se planifican y diseñan de manera independiente y aislada entre sí, con un carácter progresivamente más monofuncional, menos denso y compacto, y dónde las carreteras actúan como cordón umbilical de todo este sistema, es una ciudad compuesta por un casco histórico, arrabales, urbanizaciones marginales, espacios de bloque exento, ámbitos de urbanizaciones unifamiliares, nuevos ensanches, grandes espacios de oficina, grandes equipamientos, espacios industriales y centros comerciales. 
Figura 7. Formas urbanas en Toledo

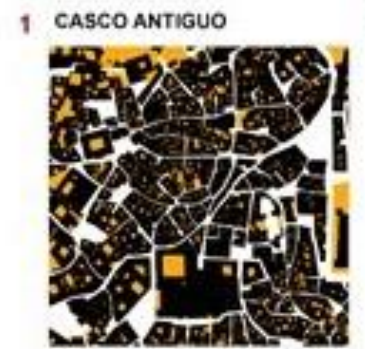

BLOQUE EXENTO

7 POLIOONO RESIOENCIAL

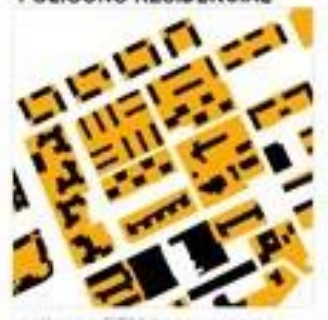

9 VIVIENDA UNIFAMILLAR

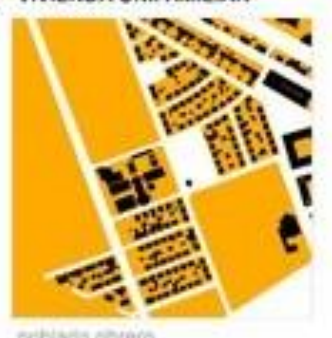

16 GRANOES EqUIPAMIENTOS

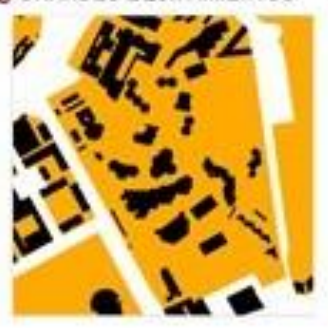

ies univenidad bover

17 POLIGONO INDUSTRIAL

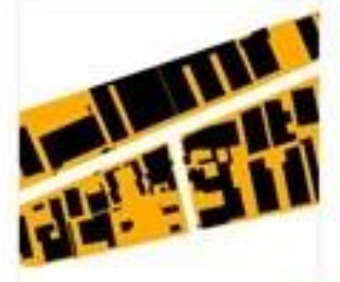

2 CASCOANTIGUO

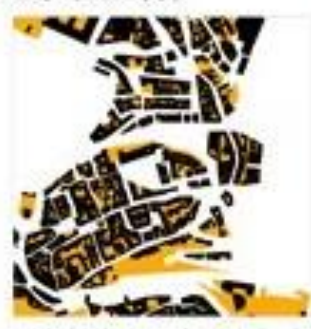

BLOQUE EXENTO

8 POLGONO RESIDENCIAL

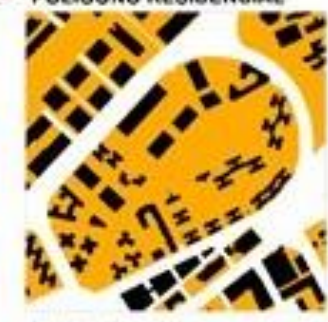

10 VIVIENDA UNIFAMILIAR

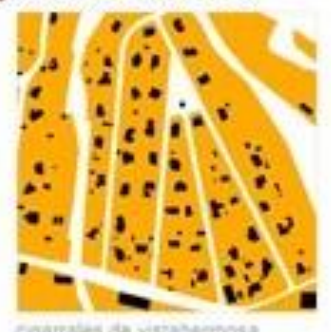

5 GRANDES ESPACIOS

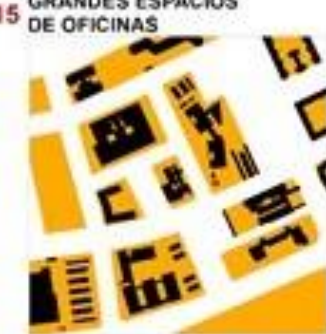

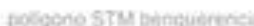

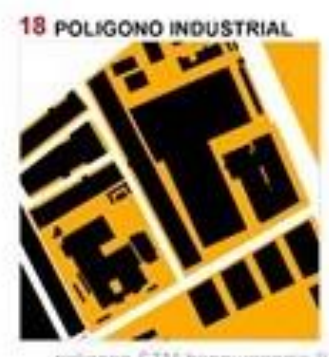

3 URBANIZACION MARGINAL

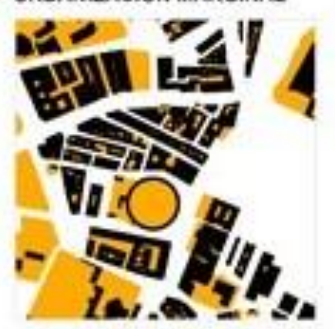

BLOQUE EXENTO

POLIONO RESIOENCIAL

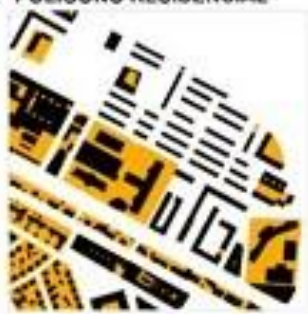

11 VIVIENDA UNIFAMILIAR

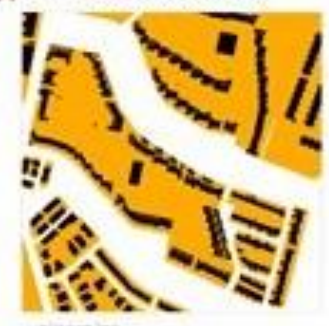

14 CENTRO COMERCIAL
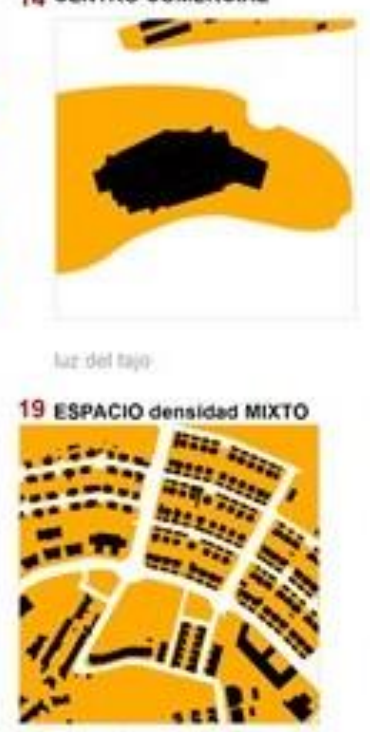

i 112000
13 NUEVO ENSANCHE

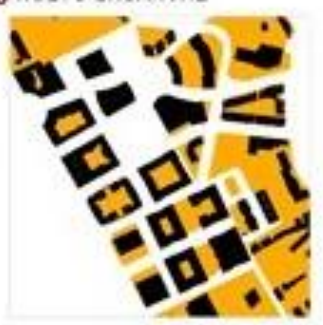

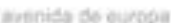

20 ESPACiO densidad Muxto

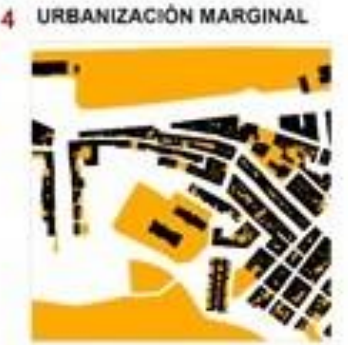

BLOQUE EXENTO

POLIGONO RESIDENCIAL

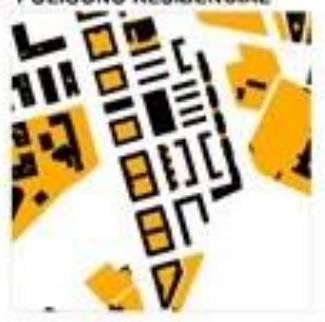

12 NUEVO ENSANCHE
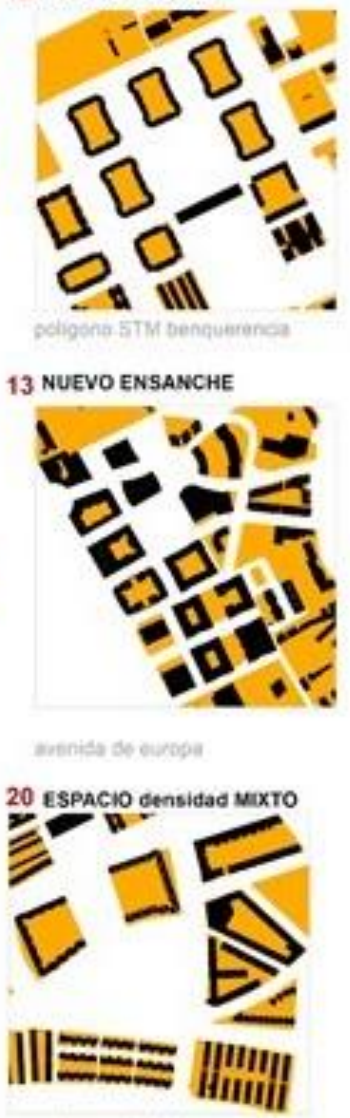

0

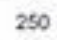

$500 \mathrm{M}$

Fuente: elaboración propia 


\section{Figura 8. Localización de las formas urbanas en Toledo}

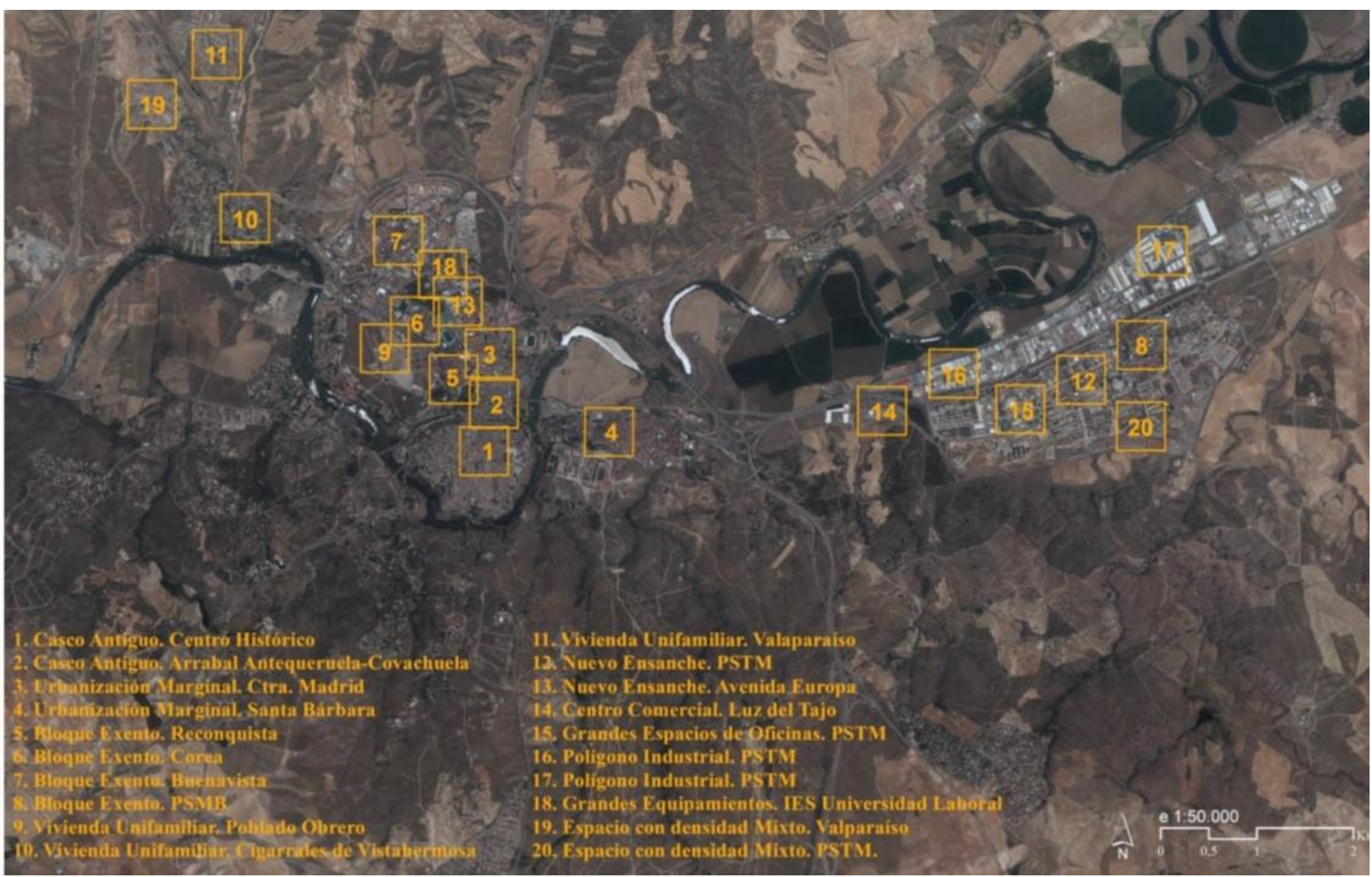

Fuente: elaboración propia

Es sobre esta complejidad y diversidad de formas urbanas sobre las que tenemos trabajar. Debemos saber cómo funcionan internamente, cómo se relacionan entre ellas, qué problemas físicos y sociales albergan, etc. Aportar conocimiento sobre estas formas urbanas supone intervenir en la estructura de la ciudad, su articulación funcional y su paisaje.

\subsection{Caracterización cuantitativa de las formas urbanas}

Una vez identificadas las formas urbanas se procede a la caracterización cuantitativa.

\section{a) Diagrama Spacemate}

Tras representar las formas urbanas de Toledo en el diagrama Spacemate (véase Figura 9), éstas pueden inscribirse en grandes ámbitos: urbano compacto tradicional, urbano, edificación en altura, suburbano, suburbano poco denso y ciudad jardín ${ }^{8}$. El resultado es el siguiente:

8 Esta delimitación de ámbito es ligeramente diferente a la propuesta por Berghauser y Haup (2010) y se basa en la propuesta realizada por Prieto et al. (2018) para el análisis de las ciudades de Castilla-La Mancha. El ámbito "urbano compacto tradicional" presenta niveles de edificabilidad altos, por encima de $1 \mathrm{~m}^{2} \mathrm{c} / \mathrm{m}^{2} \mathrm{~s}$, rangos de ocupación entre 0,20 y 0,50, cuenta con más de 3 alturas de media y una amplitud entre 0,3 y $1 \mathrm{~m}^{2} \mathrm{~s} / \mathrm{m}^{2} \mathrm{C}$. El ámbito "edificación en altura" se caracteriza por una edificabilidad media-alta y alta, $>0,5 \mathrm{~m}^{2} \mathrm{c} / \mathrm{m}^{2} \mathrm{~s}$, y con bajos valores de ocupación $<0,2$, lo que se traduce en la presencia de edificios con un número medio de plantas superior a 4 y una amplitud superior a $0,5 \mathrm{~m}^{2} \mathrm{~s} / \mathrm{m}^{2} \mathrm{c}$. El área "suburbano denso" se diferencia por edificabilidades entre 0,5 y $1,5 \mathrm{~m}^{2} \mathrm{c} / \mathrm{m}^{2}+$ y ocupaciones entre 0,3 y 0,7, siendo el rango de alturas entre 1 y 3 número de alturas y de amplitud entre 0,3 y 1 $\mathrm{m}^{2} \mathrm{~s} / \mathrm{m}^{2} \mathrm{c}$. El área "suburbano poco denso" se distingue por edificabilidades inferiores a $0,5 \mathrm{~m}^{2} \mathrm{c} / \mathrm{m}^{2} \mathrm{~s}$, ocupaciones 
- Ámbito urbano compacto tradicional. Aquí se distingue el casco histórico de Toledo.

- Ámbito urbano denso. Varias son las formas urbanas incluidas en este ámbito. Los casos de urbanización urbanización marginal "Santa Bárbara" y "Carretera de Madrid". Estas formas que en su origen reproducen paisajes rurales y de pueblo, posteriormente son sometidas a procesos de sustitución por edificios de 3/4 plantas. Se reconocen formas de bloque exento, como "Corea", "Buenavista" o "PSTM". También se incluye algunas formas vinculadas a nuevos ensanches.

- Ámbito urbano de edificación en altura. En este punto se reconocen diferentes tipos de formas urbanas, la edificación exenta, algunas fórmulas de nuevo ensanche y espacios mixtos recientes.

- Ámbito de suburbano. Destaca la forma urbana del espacio industrial. Un espacio caracterizado por la sucesión de naves, muchas veces retranqueadas y alineadas en su mayoría a linderos laterales.

- Ámbito suburbano poco denso. Ello significa que estamos ante un espacio poco denso y con grandes espacios sin edificar. En el caso de Toledo, destaca la forma urbana "Espacio Industrial. STMB-I", espacio industrial tradicional construido a lo largo de una banda paralela a la antigua nacional.

- Ámbito de la ciudad jardín. En general, reproduce el modelo de hábitat unifamiliar. En los últimos años con el fin generar mayor densidad se están promoviendo zonas que en este artículo denominado "espacios mixtos de baja y media densidad" donde se mezclan manzanas con vivienda unifamiliar y manzanas con edificios de baja más dos y baja más 3. Éstos últimos suelen estar retranqueado y tienen amplios espacios libres comunitarios. Se trata de las formas urbanas "Espacio Mixto. Vistahermosa" y "Espacio Mixto. Polígono STMB". También encontramos otras formas urbanas, como son los Grandes Espacios de Oficina.

Como se ha expuesto en el apartado teórico en el diagrama spacemate pueden solaparse diferentes configuraciones urbanas. Valores de densidad y compacidad pueden encontrarse en un rango similar y a su vez tener reglas internas diferentes. También se observa que las transiciones entre formas urbanas son suaves lo que dificulta una delimitación precisa en grandes ámbitos (García, 2017). Esta situación lleva a complementar el diagrama spacemate con el diagrama $n$.

inferiores a 0,4, un número medio de plantas inferior a 3 y una amplitud superior a $1 \mathrm{~m}^{2} \mathrm{~s} / \mathrm{m}^{2} \mathrm{c}$. El ámbito de la "ciudad jardín" queda definido por edificabilidades inferiores a $0,5 \mathrm{~m}^{2} \mathrm{c} / \mathrm{m}^{2} \mathrm{~s}$, ocupaciones inferiores a 0,2 , amplitud superior a $1 \mathrm{~m}^{2} \mathrm{~s} / \mathrm{m}^{2} \mathrm{c}$ y un número medio de alturas por debajo de 3. 


\section{Figura 9. Diagrama spacemate}

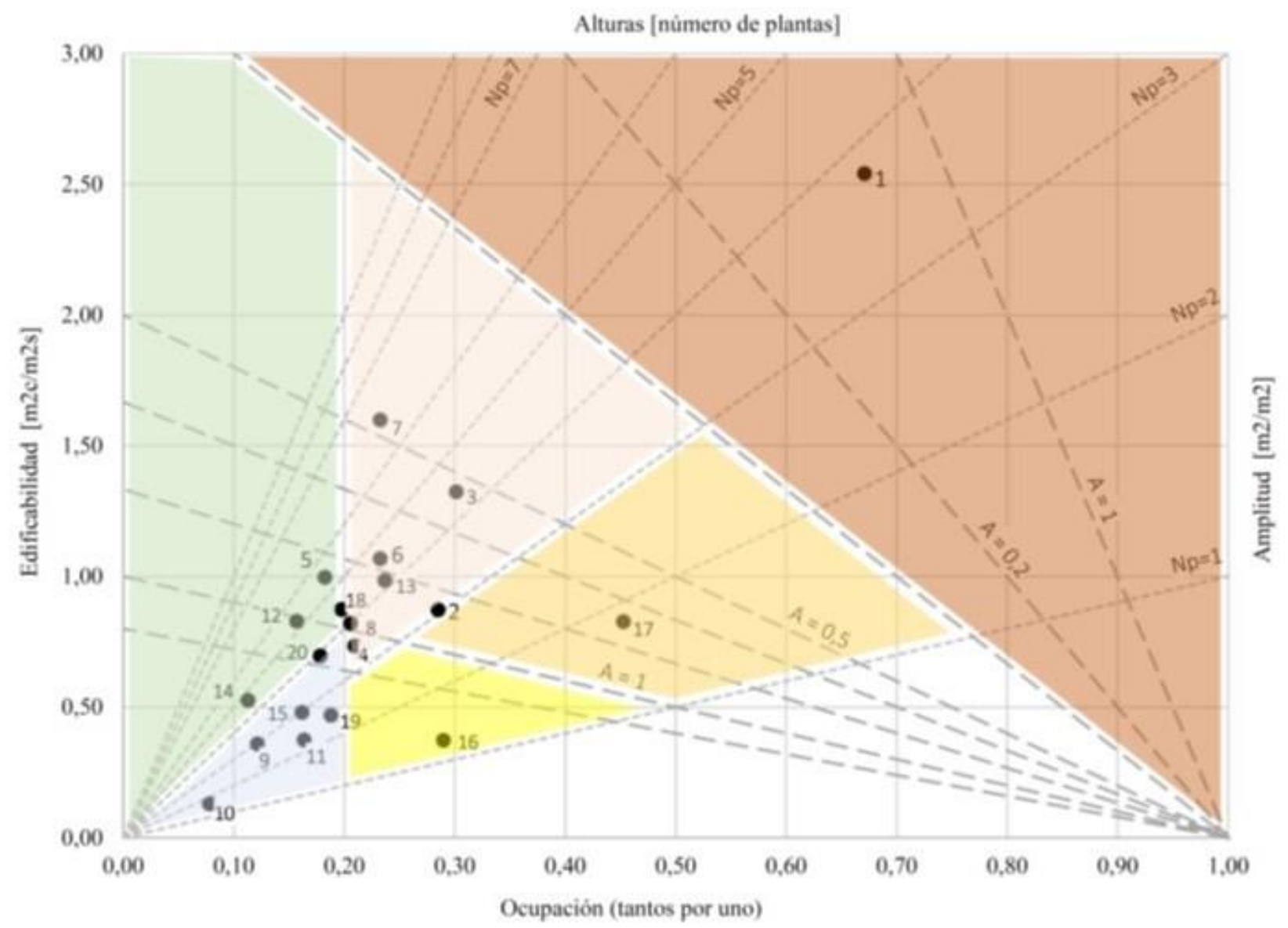

\section{CA. Centro Histórico \\ 2. CA. Arrabal \\ 3. UM. Ctra Madrid \\ 4. UM. Santa Bárbara \\ 5. BE. Reconquista}
6. BE. Corea
7. BE, Buenavista
8. BE. Poligono STMB
9. VU. Poblado Obrero
10. VU. Vistahermosa

11. VU. Valparaiso

12. NE. Poligono STMB

13. NE. Avda. de Europa

14. CC. Luz del Tajo

15. GEO Poligono STMB
16. EI. Poligono STMBI
17. EI. Poligono STMB॥
18. GE. IES Universidad Laboral
19. EM Vistahermosa
20. EM. Poligono STMB
Urbano compacto tradicional

Suburbano denso

\section{Urbano denso}

Suburbano poco denso

\section{Edificación en altura}

Ciudad Jardin

Fuente: elaboración propia

\section{b) Diagrama $\mathrm{n}$}

Este diagrama ayuda a establecer diferencias y reconocer matices entre formas urbanas en relación a la traza, concretamente a la pauta que describen el tamaño de las manzanas y la cantidad de espacio libre público (véase Figura 10). Como se ha descrito en el apartado teórico este diagrama, comparando la cantidad de espacio público, ancho medio de las calles y la red de calles ayuda a establecer una tipología sobre el grado de sobredimensionamiento del espacio público.

- Formas urbanas con un grado elevado de sobredimensionamiento del espacio público. Presentan una anchura media de calle superior a 30 m., una tara entre el $40 \%$ y $60 \%$ y una densidad de 
la red de calles entre el 0,01 y el 0,02 ml/m². Aquí tenemos diferentes casos, nuevos ensanches, grandes espacios de oficinas, espacios mixtos, superficies comerciales y espacios industriales. Todos estos casos presentan un diseño basado en grandes manzanas de propiedad colectiva y espacios públicos -viales y zonas verdes- que lo envuelven y aíslan en muchos casos.

- Formas urbanas con un grado medio de sobredimensionamiento del espacio público. Se diferencias dos grupos. El grupo de formas en las que la tara está por debajo del $40-50 \%$ y aquellas por encima. Las que están por debajo de la tara señalada y presentan una densidad de la red de calles inferior a 0,02 ml/m² son el nuevo ensanche de "Avenida Europa" y el bloque exento de "Buenavista". Las que están por encima de la tara señalada y tienen una densidad de la red de calles superior a 0,02 ml/m² son bloque exento de "Reconquista", "PSMB" y "Corea", junto con la urbanización marginal de "Ctra. Madrid" y "Santa Bárbara". Aunque se trata de espacios con una densidad y compacidad de tipo medio, la diferencias entre el primer grupo y el segundo grupo radica en el criterio de diseño vinculado a la cantidad de espacio libre privado. En el primer grupo la superficie de espacio libre privado es mucho mayor que en el segundo grupo.

- Formas urbanas con un grado bajo de sobredimensionamiento del espacio público. Aquí también se diferencian dos grupos. El grupo de formas en las que la tara está por debajo del $40 \%$ y aquellas por encima. Las que están por debajo y tienen una densidad de la red de calles en torno al $0,02 \mathrm{ml} / \mathrm{m}^{2}$ son las formas de vivienda urbana unifamiliar, el espacio mixto "Vistahermosa" y los espacios industriales. Las formas que tienen una densidad de la red de calles por encima al $0,03 \mathrm{ml} / \mathrm{m}^{2}$ son las vinculadas a casco antiguo.

En el planeamiento y ordenación de la ciudad, desde comienzos del siglo XX, se ha ido imponiendo el aumento de $\mathrm{m}^{2}$ de espacio libre público y privado como rasgo de modernidad y vinculado a la idea de confort y progreso. Este hecho ha llevado a un sobredimensionamiento y una consiguiente merma en la interacción en el espacio público (López de Lucio \& Hernández, 1995; Gehl, 2006; Rodríguez-Tarduchy 2011). Asimismo, estos incrementos conllevan un mayor coste económico y consumo de recursos tanto en la urbanización como en su posterior mantenimiento. En consecuencia, uno de los retos de urbanistas y técnicos es tratar con cuidado la vida entre los edificios, la escala y superficie de los elementos físicos que la configuran -tamaño de la manzana, tamaño de la parcela, posición del edificio respecto a la alineación, proximidad entre edificios, etc. -. Como observa Berman (1996) las calles estrechas y parcelas pequeñas incrementan las oportunidades para la interacción social. En esta línea Gehl (2006, p. 77) sostiene que "a distancias cortas, la cantidad e intensidad de información se incrementa enormemente porque los demás sentidos pueden empezar entonces a complementar el sentido de la vista". 


\section{c) Diagrama de mezcla urbana funcional}

Hasta este punto solamente se han considerado aspectos morfológicos. El tercer paso en la caracterización cuantitativa de las formas urbanas de Toledo es la incorporación de aspectos funcionales, en este caso, los usos. Siguiendo la propuesta de van den Hoek (2008) descrita en el apartado 2 se ha confeccionado la Figura 11. Como resultado se establecen diferentes tipos de formas urbanas según presencia de usos:

- Espacios multifuncionales. Se trata de un grupo de formas urbanas que tienen en torno al 50 $60 \%$ de uso residencial. Dentro de este grupo hay espacios urbanos como el "Casco Antiguo. Centro Histórico", "Urbanización Marginal. Santa Bárbara" o "Bloque Exento. Reconquista" que incorporan valores de uso trabajo/comercio en torno al 20-30 \% y 10_ 20 \% de equipamientos, mientras que otros como "Casco Antiguo. Arrabal", "Bloque Exento. Palomarejos" y "Grandes Equipamientos. IES. Universidad Laboral", albergan valores en torno al $10-20 \%$ de uso trabajo/comercio y $20-25 \%$ de uso equipamientos.

- Espacios bifuncionales. En este grupo se diferencian aquellos con una componente de uso residencial destacado (60-80\%) y dominante (>80\%). En los segundos, hay formas urbanas diferentes como "Urbanización Marginal. Carretera de Madrid", "Bloque Exento. Polígono STMB", "Bloque Exento. Buenavista" y "Vivienda Unifamiliar. Vistahermosa", con valores en torno al $10-15 \%$ de uso trabajo/comercio y equipamientos. Aunque estas formas urbanas no son concebidas para albergar usos no residenciales, procesos de sustitución de uso y una planificación tendente a incorporar recualificar con dotaciones.

- Espacios monofuncionales. En este grupo se diferencian tres arquetipos de formas según el nivel de especialización: los espacios industriales -polígonos industriales-, los espacios de vivienda unifamiliar y los grandes paquetes de suelo dedicados a superficies comerciales exclusivamente. 
Figura 10. Diagrama $n$

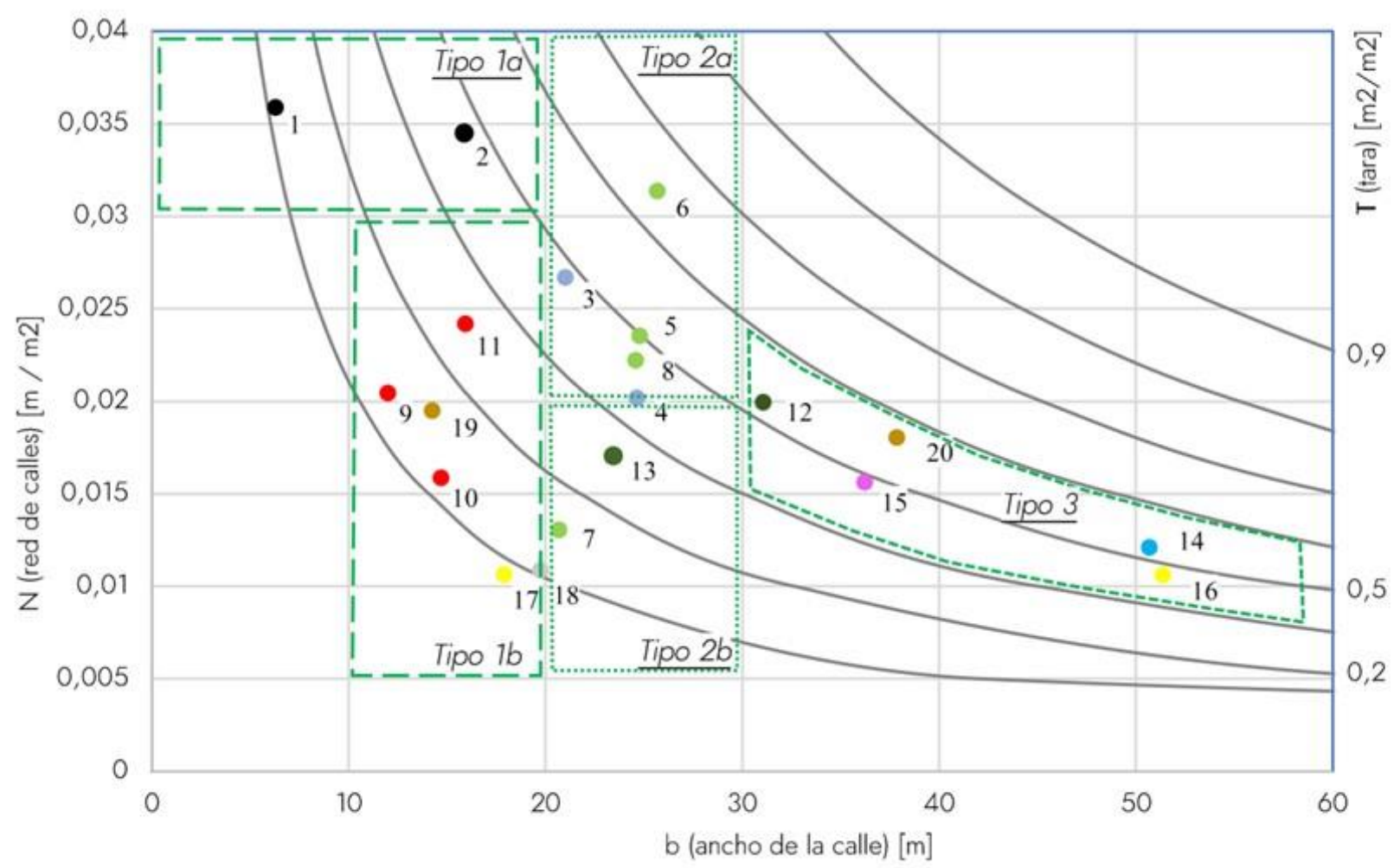
1. CA. Centro Histórico
2. CA. Arrabal
6. BE. Palomarejos-Corea
7. BE. Buenavista
3. UM. Carretera de Madrid
8. BE. PSMB
UM. Santa Bárbara
9. VU. Poblado Obrero
5. BE. Reconquista
10. VU. Vistahermosa
16. EI. PSMB-1
17. EI. PSMB-II
18. GE. IES Univ. Laboral
19. EM. Vistahermosa
20. EM. PSMB

Fuente: elaboración propia

Sobredimensionamiento del espacio público: Grado Bajo Tipo la (Manzanas de tamaño medio y pequeño y poco espacio libre a su interior).

Tipo 1b (Manzanas de tamaño medio y pequeño y espacio libre

privado superior a la mitad de la huella edificada)
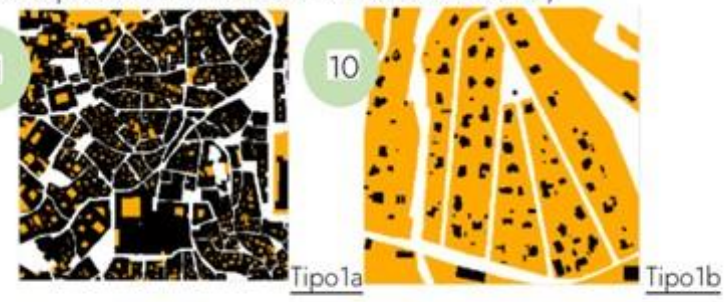

Sobredimensionamiento del espacio público: Grado Medio Tipo 2a (Manzanas de tamaño medio con espacio libre privado similar a la mitad de la huella edificada).

Tipo $2 b$ (Manzanas de gran tamaño y espacio libre privado superior a la mitad de la huella edificada).

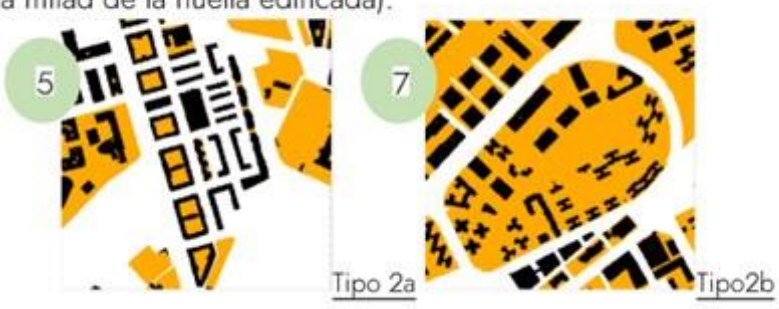

Sobredimensionamiento del espacio público: Grado Alto Tipo 3 (Manzanas de gran tamaño y rodeada por amplios viales)

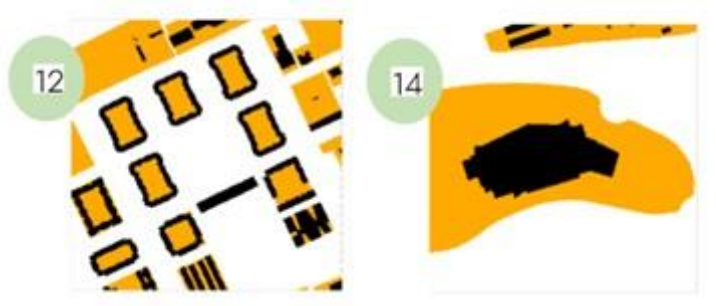




\section{Figura 11. Formas urbanas según mezcla de usos}

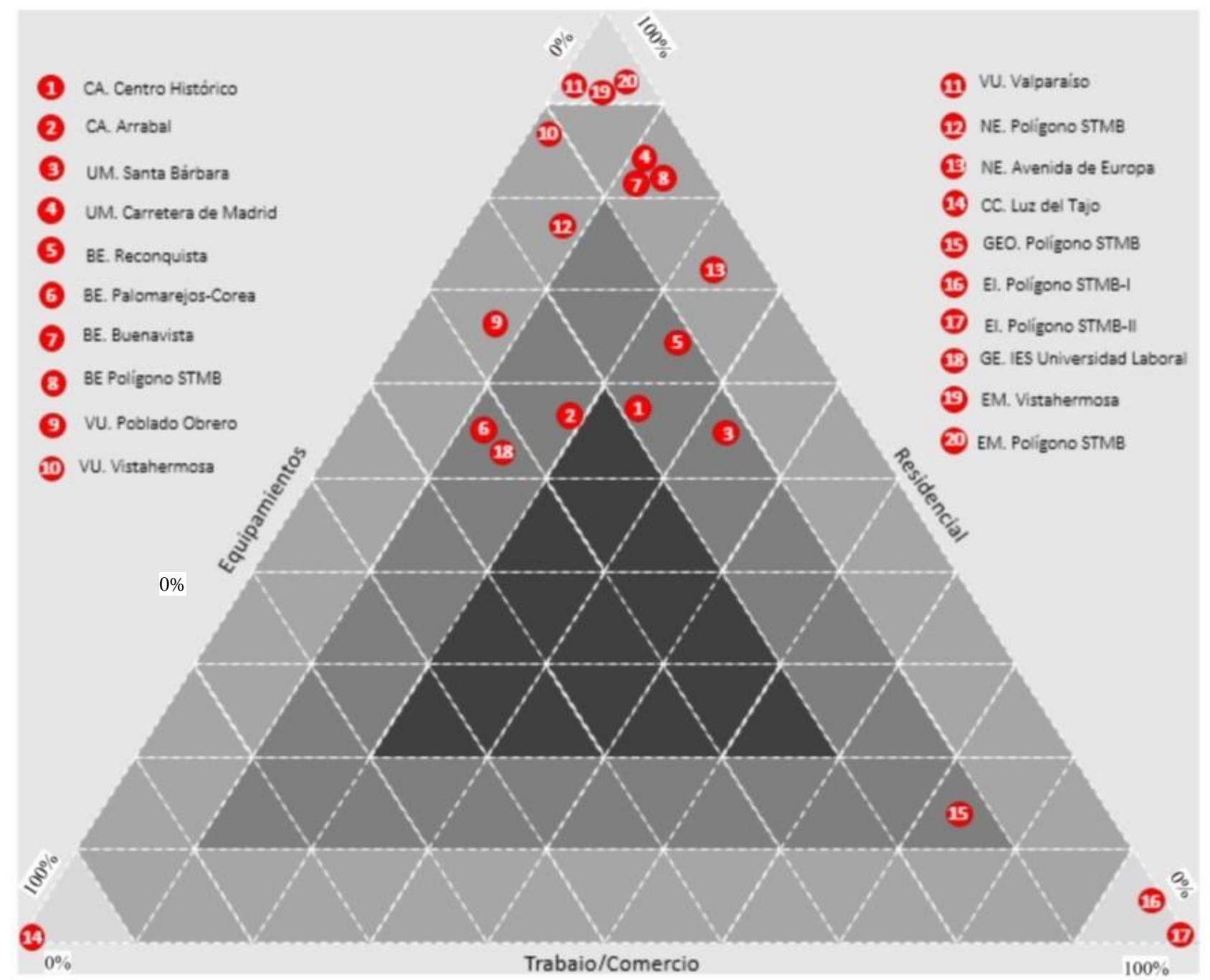

Fuente: elaboración propia

Complementando el potente carácter visual de este diagrama, hemos elaborado una tabla en la que comparamos las formas urbanas en función del año de construcción, número de viviendas, población y mezcla de usos de suelo (véase Tabla 4). El resultado constata, para el caso de Toledo, la creciente zonificación espacial y funcional del espacio urbano a lo largo del siglo XX. Esta situación, descrita para otros lugares (Panerai et al., 1986) responde, en buena medida, al uso de la técnica del zoning (zonificación en español). Se trata de un instrumento que, para distintas partes de la ciudad existente o proyectada, adscribe determinados usos, actividades o tipología edificatorias. Para el caso de Toledo se observa que la planificación programática basada en el zoning ha llevado a la progresiva quiebra en la mezcla de funciones y, en consecuencia, al empobrecimiento de la vida urbana, así como el incremento del uso del vehículo privado para los desplazamientos. 


\section{Tabla 4. Formas urbanas según año de construcción, densidad y usos}

\begin{tabular}{|c|c|c|c|c|c|}
\hline Ámbitos en Toledo & $\begin{array}{c}\text { Año de } \\
\text { Construcción } \\
\text { (dato medio } \\
\text { aproximado } \\
\text { para el ámbito } \\
\text { de estudio) }\end{array}$ & $\begin{array}{l}\text { Número de } \\
\text { Viviendas } \\
\text { (dato } \\
\text { aproximado) }\end{array}$ & $\begin{array}{l}\text { Población } \\
\text { (2,51 personas } \\
\text { por hogar) }\end{array}$ & $\begin{array}{l}\text { Densidad } \\
(\mathrm{Hab} / \mathrm{Ha})\end{array}$ & $\begin{array}{l}\text { Índice de } \\
\text { Diversidad } \\
\text { de Shannon }\end{array}$ \\
\hline $\begin{array}{l}\text { CA. Centro Histórico (espacio } \\
\text { intramuros) }\end{array}$ & Antes 1900 & 2869 & 7201 & 288 & 0,788 \\
\hline CA. Arrabal Covachuelas-Antequeruela & Antes 1900 & 1517 & 3808 & 152,3 & 0,435 \\
\hline UM. Carretera de Madrid & $1900-1950$ & 1745 & 4380 & 175,2 & 0,541 \\
\hline UM. Santa Bárbara & $1940-1960$ & 1541 & 3868 & 154,7 & 0,318 \\
\hline BE. Reconquista & $1940-1950$ & 1273 & 3195 & 127,8 & 0,463 \\
\hline VU. Poblado Obrero & $1940-1950$ & 421 & 1.057 & 42,3 & 0,224 \\
\hline BE. Palomarejos-Corea & $1950-1960$ & 1537 & 3858 & 154,3 & 0,508 \\
\hline BE. Polígono de Sta. $M^{a}$ Benquerencia & 1970 & 1743 & 4375 & 175 & 0,356 \\
\hline GE. IES Universidad Laboral & 1970 & 206 & 517 & 20,7 & 0,46 \\
\hline BE. Buenavista & $1970-1980$ & 1707 & 4285 & 171,4 & 0,515 \\
\hline VU. Vistahermosa & $1970-1980$ & 115 & 289 & 11,5 & 0,086 \\
\hline El. Polígono de Sta. Ma Benquerencia-l & $1970-1980$ & 0 & 0 & 0 & 0,169 \\
\hline NE. Polígono de Sta. Mª Benquerencia & 1980 & 1468 & 3685 & 147,4 & 0,346 \\
\hline El. Polígono de Sta. Mª Benquerencia-ll & 1980-1990 & 0 & 0 & 0 & 0,262 \\
\hline NE. Avenida de Europa & 1990 & 1070 & 2686 & 107,4 & 0,452 \\
\hline \multirow{2}{*}{$\begin{array}{l}\text { EM. Polígono de Sta } M^{a} \text { Benquerencia } \\
\text { GEO. Polígono de Sta. } M^{a} \\
\text { Benquerencia }\end{array}$} & 1990 & 721 & 1810 & 72,4 & 0,316 \\
\hline & 1990-2000 & 337 & 846 & 33,8 & 0,294 \\
\hline VU. Valparaíso & 2000 & 942 & 2364 & 94,6 & 0,2 \\
\hline CC. Luz del Tajo & 2000 & 0 & 0 & 0 & 0,134 \\
\hline \multirow{2}{*}{ EM. Valparaíso } & $2000-2010$ & 1574 & 3951 & 158 & 0,228 \\
\hline & Promedio * & 1039,30 & 2608,75 & 104,34 & 0,355 \\
\hline
\end{tabular}

* Se ha marcado en verde aquellas formas urbanas con datos superiores al promedio.

Fuente: elaboración propia

d) La influencia de la forma urbana en la mezcla de usos

Tras el realizar un análisis factorial, se han considerado 4 componentes (véase Figura 12), los cuales recogen un $89,104 \%$ de la variabilidad total. A partir de estos componentes se ha efectuado un modelo predictivo (modelo de regresión lineal múltiple) del índice de diversidad de usos (denominado índice H). El resultado arroja un alto grado de ajuste (R2 = 86,8 \%) y que éste resultó ser significativo $(p<0.05)$ lo cual permite su uso con carácter predictivo. A partir del cuadro de coeficientes se establece el modelo:

$$
\text { Índice } \mathrm{H}=0.355+0.148 * \mathrm{C} 2+0.067 * \mathrm{C} 1-0.053 * \mathrm{C} 4 \text {, }
$$

donde C1, C2 y C4 denotan los primer, segundo y cuarto componentes extraídos en el análisis factorial respectivamente. Obsérvese en la Figura 12 que todos los términos resultaron ser significativos a excepción de la tercera componente, C3. También se investigaron otro tipo de relaciones -no lineales- entre el índice de uso y C3, pero no se reconoció ningún otro patrón de forma. Este hecho implica que, los indicadores relacionados con la misma no contribuyen a explicar, de forma representativa, el índice de uso. El valor de los coeficientes del modelo y su signo 
contribuyen a cuantificar la relación de las componentes con el índice de uso. Así pues, en términos absolutos, incrementos producidos en segunda componente son los que mayor incremento producen en el índice de uso, seguido de los producidos con la primera componente. El hecho de que el coeficiente que acompaña a CP4 sea el más pequeño -en valor absoluto- implica que ésta es la menos influyente de las tres en la respuesta. Ahora bien, puesto que los componentes están correlacionados de forma positiva o negativa con las variables indicadores y que el signo de los coeficientes que acompañan a cada componente en el modelo es distinto, la relación indicador-índice de uso debe interpretarse de la siguiente manera: las variables correlacionadas de manera fuerte y directa con C2 y $\mathrm{C} 1$ incrementan el índice $\mathrm{H}$, mientras que las variables con correlación fuerte y directa con C4 hacen decrecer la diversidad de uso. Las variables que, aun teniendo una fuerte correlación, tienen valores de correlación de signo negativo con las componentes experimentarán, por tanto, el efecto contrario respectivamente. En el apartado de resultados se interpretarán estas relaciones en términos de las variables indicadores recogidas en este estudio.

En síntesis, podemos decir que mientras que el análisis factorial nos permite identificar un conjunto de componentes -agrupación de propiedades espaciales-, el método inferencial genera un modelo predictivo sobre la influencia de esas componentes en la mezcla de usos. (véase Figura 12).

A la hora de predecir la diversidad funcional o mezcla urbana de usos hay que contemplar la significación, los coeficientes y el signo (positivo o negativo) de cada componente en el modelo, así como las correlaciones entre cada variable e indicador espacial y las componentes. Los resultados reflejan: (a) que la configuración espacial influye en la mezcla de usos de suelo; (b) las propiedades espaciales ligadas con la segunda componente (superficie ocupada en planta por la edificación, superficie construida sobre rasante, ocupación neta, edificabilidad neta, amplitud) son las que más afectan a la diversidad de uso y, por tanto, las más relevantes para tener en cuenta en la planificación urbana; (c) aquellas propiedades conectadas con la primera (número de viviendas, número de manzanas, número de parcelas, superficie de espacio peatonal en la red viaria, longitud de la red de calles e intersecciones) y cuarta componente (superficie de espacio público, superficie sin edificar privada, superficie de espacio dedicado a la circulación de vehículo y aparcamiento y ancho de calle) son importantes, pero tienen menos relevancia.

Teniendo en cuenta esto, a continuación, se interpreta el valor de las propiedades espaciales y su influencia en la mezcla de usos. 
Figura 12. Pasos en el análisis factorial e inferencial

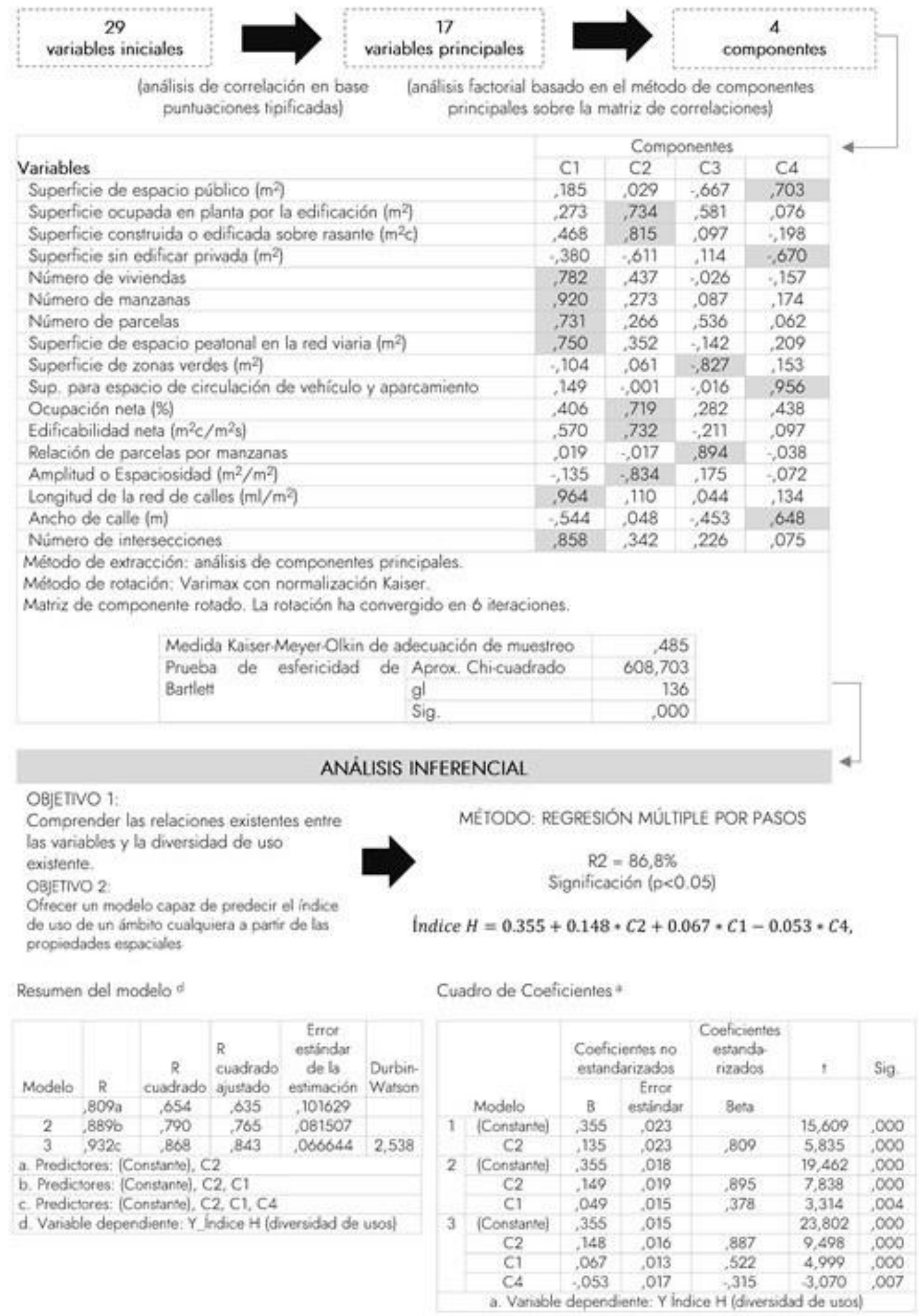

Fuente: elaboración propia

El primer componente (C1) tiene seis variables - número de viviendas, número de manzanas, número de parcelas, superficie de espacio peatonal en la red viaria, longitud de la red de calles e intersecciones-. Este componente informa a la planificación y diseño urbano con los siguientes criterios: cuanto mayor número de manzanas hay, más parcelas y edificios existen al interior de las 
manzanas, más longitud de calles, más intersecciones y más superficie de espacio peatonal alrededor de las manzanas mayor índice de mezcla funcional tendremos en nuestra ciudad. Estos criterios refuerzan y confirman planteamientos urbanísticos desarrollados por otros autores. Por ejemplo, Jacobs (2011) señala que cuando las manzanas son demasiado grandes se incrementan las distancias, pero éstas no deberían ser demasiado pequeñas para generar alta permeabilidad sin caer en una proporción de espacio construido relativamente menor que la inversión en la red de calles. Por otro lado, Parker (1994) sostiene que la planificación urbana debe considerar en sus instrumentos de control del uso de suelo la heterogeneidad de usos, ya que la ubicación de uno cerca de otro reduce la distancia de viaje y favorece la interacción social. Esta idea se alinea con Hillier (1996) cuando propone que la morfología del sistema de calles en la ciudad actúa de interfaz del espacio público y los edificios, condición importante para posibilitar los encuentros e interacción. Hillier (1996), Karimi (1997) o Siksna (1997) muestran que la centralidad urbana está asociada con efectos de la accesibilidad resultado del tamaño de las manzanas. Las manzanas de menor tamaño incrementan la permeabilidad con los entornos, reducen tiempo de viaje, aumenta la interacción socioeconómica, etc.

El segundo componente (C2) comprende cinco indicadores - superficie ocupada en planta de la edificación, la superficie edificada o construida sobre rasante, la ocupación neta, la edificabilidad neta y la espaciosidad-. Esto informa a la planificación y diseño urbano con los siguientes criterios: cuanto mayor superficie ocupada, superficie edificada, ocupación neta, edificabilidad neta y menor amplitud, mayor índice de mezcla funcional tendrá nuestra ciudad. En consecuencia, se debe conjugar un planteamiento y diseño urbano que favorezca la predominancia de espacios ocupados frente a espacios libres. Se trata de reducir el número de desplazamientos motorizados, permitiendo, por tanto, la presencia de mayor número de edificios con diferentes usos en un mismo espacio. Cabe señalar que el indicador espaciosidad presenta un signo negativo, eso significa que cuanto más grande es este valor menor será la diversidad de usos. Este dato sustenta planteamientos previos que conectan con la crítica al exceso de espacios libres propuestos por el Movimiento Moderno. Una proporción elevada de este tipo de espacios (muchas veces por encima del 50-60\%) no solo genera dificultad de mantenimiento y conservación, sino que también afecta a su uso y a la percepción que de dichos espacios (López de Lucio, 1993; Lopez de Lucio \& Hernández, 1995; RodríguezTarduchy, 2011). La idea de aglomeración por proximidad y contigüidad es clave para explicar las relaciones y encuentros. Mientras que la proximidad se relaciona con la existencia de edificios próximos pero separados por espacios abiertos, la adyacencia refiere a una agregación contigua espacialmente. En esta línea argumental, el tamaño, ocupación y edificabilidad de las manzanas se vuelven determinantes (Netto, 2017).

El tercer componente (C3) incluye dos indicadores -superficie de zonas verdes y relación de parcelas por manzanas-. Aunque la presencia de zonas verdes es importante para realizar actividades de ocio 
y esparcimiento, según establece el modelo predictivo aquí propuesto ésta no influye de forma relevante en la diversidad funcional. El verde en la ciudad no debe considerarse como un gran espacio, sino que debe aproximarse como una red de espacios de diferente tamaño en ciertas partes de la ciudad (Jackson, 2003). Asimismo, el verde en la ciudad también debe estar en las calles y plazas, ya que reduce la contaminación, modera las temperaturas o contribuye a hacer más sostenible el sistema de drenaje urbano (Higueras, 2009).

El cuarto componente (C4) engloba cuatro indicadores -la superficie de espacio público, la superficie sin edificar privada, el espacio de circulación y aparcamiento de vehículos y la anchura (promedio) de la calle-. Aquí encontramos tres valores con signo positivo y uno con signo negativo (véase la matriz de componentes de la Figura 12). Es decir, cuanto mayor superficie pública, superficie de espacio de circulación y de aparcamiento y anchura de la calle, la influencia en la diversidad de usos será menor. Esto se traduce en que el sobredimensionamiento del espacio público tiene efectos negativos en la vitalidad urbana. Por el contrario, una mayor superficie privada sin edificar significaría, según nuestro modelo predictivo, una mayor mezcla funcional. Este dato puede ser ciertamente contradictorio con evidencias relacionadas con el funcionamiento de los nuevos ensanches. Tal y como señalan López de Lucio \& Hernández (1995), un incremento de superficie libres privadas -interiores de manzanas- juegan un papel negativo en el uso del espacio público y el desarrollo de actividades.

\section{Discusión y conclusiones}

La elaboración de este estudio permite extraer una discusión y conclusiones en torno a aspectos teórico-interpretativos, relativos al método y fuentes, sobre los resultados y de cara a la futura investigación.

Desde el punto de vista teórico-interpretativo en los últimos años se reclama un mayor conocimiento sobre la manera en que los procesos socioeconómicos están mediatizados por el mundo material. Aunque este hecho puede aprehenderse desde múltiples aproximaciones, en este artículo hemos focalizado la atención en la configuración del espacio urbano - las formas o morfologías urbanascomo una condición material que debe distinguirse y examinarse por su influencia en la vida de una ciudad. Reconociendo que los avances en el campo de la morfología urbana descansan en la intersección de varias disciplinas -geografía, arquitectura, urbanismo, historia, sociología, económicas, etc. - y no hay una definición unívoca del concepto de forma urbana, sí hay un amplio consenso en el objeto de estudio. Éste refiere a la manera en que se disponen u organizan espacialmente las manzanas, las parcelas, los edificios (espacio privado o parcelado) y la red de calles, zonas verdes y plazas (espacio público o libre), así como a las personas (agentes) y procesos que la moldean. Este artículo, sostiene que la configuración espacial de los elementos físicos del espacio privado y público constituyen un material de trabajo propio en la constitución de las formas 
urbanas. Así pues, estos elementos físicos permiten identificar diferentes formas urbanas en el conjunto de una ciudad. Por otro lado, se sostiene que las propiedades espaciales de cada morfología condicionan la vitalidad urbana, en este caso, la diversidad funcional -representada a partir de la mezcla de usos del suelo-.

Desde el punto de vista del método y fuentes, este trabajo combina el enfoque morfogenético y cuantitativo y se apoya en el manejo de diversas fuentes de información, y especialmente, en el uso de la cartografía digital catastral a través de los sistemas de información geográfica. El uso de Catastro evita la generalización de información que se deriva del empleo de otras fuentes como CORINE, SIOSE, LIDAR, etc. Aunque estas fuentes son verdaderamente útiles a escala territorial, como señalan Vanderhaegen \& Canters (2017), la escala de resolución de SIOSE o CORINE ofrece ámbitos o recintos espaciales ligados a categoría o tipos de suelo que, o bien, pueden incorporar diferentes morfologías, o bien, ocultan el carácter multifuncional bajo un uso de suelo predominante. Las técnicas cuantitativas empleadas en este trabajo se demuestran útiles para aportar conocimiento en la caracterización y análisis comparativo entre formas urbanas. A pesar de que se trata de técnicas reproducibles en otros lugares y contextos, observamos que las condiciones propias de cada lugar deben servir de guía y referencia a la hora de interpretar resultados.

Respecto a los resultados, este estudio constata la influencia de la configuración espacial en la diversidad funcional. Hemos detectado que la manera en que se dispone u ordena espacialmente los elementos del espacio público y privado genera ciertas cualidades y/o propiedades espaciales que influyen en una mayor o menor diversidad funcional. Esto no significa que tomemos partido por un determinismo de la forma urbana sobre la vida urbana. Somos conscientes que la complejidad de la ciudad no puede reducirse a la mera manipulación del espacio físico.

Como ya argumentaba Alexander (1965) la planificación y diseño no puede reproducir la complejidad de las características de las formas urbanas que se han desarrollado de manera incremental e interactivamente con las condiciones socioeconómicas a lo largo de la historia. A pesar de ello, la investigación efectuada en este trabajo aporta criterios que pueden servir de guía a la planificación y diseño del espacio urbano. Es necesario organizar la ciudad en base a manzanas no demasiado grandes, que alberguen variedad de parcelas y edificios con múltiples usos. Una ordenanza capaz de dar cabida a estos criterios espaciales ofrecerá más posibilidades de albergar múltiples usos y, a la larga, de reunir y potenciar encuentros y acontecimientos; en suma, de hacer una ciudad más viva y dinámica. La producción de ciudad no debe generar formas urbanas aisladas sino buscar contigüidad y permeabilidad a través de espacios públicos sin sobredimensionar y de diferentes tamaños.

Toledo, como caso de estudio, ofrece una gran variedad de formas urbanas y ha servido para ejemplificar la interrelación de tres temas. El primero, el carácter independiente y universal de los 
elementos físicos del espacio público y privado. El segundo, la materialización de estos elementos físicos está contextualizada, depende de un contexto socioeconómico y territorial local y supralocal. El tercero, a partir del análisis de las propiedades espaciales de cada morfología se pueden extraer criterios que guíen la planificación y diseño en favor de una mayor diversidad funcional.

Finalmente, el presente trabajo de investigación continua y refuerza una línea de trabajo centrada en conocer con más profundidad e interpretar el grado de influencia del espacio (aquí analizado a través de las formas urbanas) en la actividad humana (aquí analizado a través de la presencia de mezcla de usos en el espacio urbano). Futuros estudios deberán nutrirse con otras variables espaciales, técnicas y fuentes.

Agradecimientos: Este trabajo de investigación es desarrollado en el marco del Proyecto de Investigación de la UCLM [CGT180016] "Dinámicas urbanas: una aproximación morfológica y funcional. Interrelaciones entre configuración urbana, movilidad y actividades económicas". Asimismo, este trabajo deriva en sus planteamientos teóricos y metodológicos de la estancia postdoctoral en la Bartlet School of Architecture (UCL) por parte del primer autor en el marco del Subprograma de Movilidad dentro del Programa Estatal de Promoción del Talento y su Empleabilidad, del Plan Estatal de Investigación Científica y Técnica y de Innovación 2016-2017 del Ministerio de Educación, Cultura y Deporte (José Castillejo-Modalidad B).

Declaración responsable: Todas/os las/os autoras/es se comprometen a comunicar cualquier conflicto de intereses existente o potencial en relación a la publicación de su artículo. Eloy Solís ha impulsado y coordinado el artículo, trabajando en cada una de las partes y haciendo una revisión global. Irene García ha sido responsable del análisis estadístico e inferencial. Borja Ruiz-Apilánez y José María Ureña han trabajado en la selección de variables e indicadores así como en la parte de resultados. Inmaculada Mohíno y Eloy Solís han trabajado en la parte teórica y metodológica, así como en la redacción y revisión final del artículo. 


\section{Bibliografía}

Ahedo, A. (2017). La evolución urbana de Toledo. Toledo y Grupo de Ciudades Patrimonio de la Humanidad. Comisión de Ciudad y Patrimonio. Retrieved from http://www.toledo.es/wpcontent/uploads/2017/07/prueba-toledo-2.pdf

Alexander, C. (1965). A city is not a tree. Architectural Forum, 122(1/2), 558-562.

Alexander, C. Ishikawa, S., \& Jacobson, M. (1977). A Pattern Language: Towns, Buildings, Construction. New York: Oxford University Press.

Beaujeu-Garnier, J., \& Chabot, G. (1970). Tratado de Geografía urbana. Barcelona: Vicens-Vives.

Benfield, K., Raimi, M., \& Chen, D. (1999). Once there were greenfield: how urban sprawl is undermining America's environment, economy and social fabric. NRDC.

Benito, F. (1998). La ciudad de Toledo. Perspectivas. Cuadernos Hispanoamericanos, 573, 4552.

Berghauser, M., \& Haupt, P. (2010). Spacematrix. Space, Density and Urban Form. Rotterdam: NAI Publishers.

Berghauser, M., \& Haupt, P. (2007). The relation between urban form and density. Urban Morphology, 17(1), 142-146.

Berghauser, M., \& Haup, P. (2005). The Spacemate: Density and the typomorphology of the urban fabric. Nordisk Arkitekturforskning, 4, 55-68.

Berman, M.A. (1996). The transportation effects of neo-traditional development. Journal of Planning Literature, 10(4), 347-363.

Bohl, C., \& Plater-Zyberk, E. (2006). Building community across the rural-to-urban transect. Places, 18(1), 4-17.

Boyko, C., \& Cooper, R. (2011). Clarifying and reconceptualising density. Progress in Planning, 76, $1-61$

Burton, E. (2000). The compact city: just or just compact. A preliminary Analysis. Urban Studies, 37(11), 1969-2001.

Busquets, J. (2000). Toledo y su futuro. El Plan Especial del Casco Histórico de Toledo. Ayuntamiento de Toledo, Caja de Castilla-La Mancha, Empresa Municipal de la Vivienda de Toledo, S.A.

Campos, M. L., Díaz, J. L. García, D., Martín, J. \& Sánchez-Horneros, A. (1988). Toledo: estudio geográfico-urbanístico del casco histórico. In Toledo ¿ciudad viva?¿i ciudad muerta? (pp. 3-74). 
Simposio celebrado en el Palacio Lorenzana, April 26-30, 1983. Toledo: Colegio Universitario de Toledo.

Capel, H. (2016). Forma urbana en la ciudad postcapitalista. Revista bibliográfica de Geografía y Ciencias Sociales, XXI (1177). Retrieved from http://www.ub.edu/geocrit/b3w-1177.pdf

Capel, H. (1975). Capitalismo y morfología urbana en España. Barcelona: Libros de la Frontera.

Carpio, J., Benito, M., Lamíquiz, P., \& Pozueta, J. (2018). Medir la mezcla de usos como complementariedad funcional y espacial. Los tejidos de la burbuja inmobiliaria en el Área Metropolitana de Madrid (1990-2012). In Ciudad y formas urbanas. Perspectivas Transversales. Actas del II Congreso Internacional ISUF-h celebrado Zaragoza.

Cebrián, F., \& Panadero, M. (Coords.) (2013). Ciudades medias. Formas de expansión futura. Biblioteca Nueva.

Cervero, R. (1998). Transit Metropolis, a Global Inquire. Washington: Island Press.

Clifton, K., Ewing, R., Knaap, G., \& Song, Y. (2008). Quantitative analysis of urban form: a multidisciplinary review. Journal of Urbanism: International Research on Placemaking and Urban Sustainability, 1(1), 17-45.

Colquhoun, A. (1989). Twentieth-Century Concepts of Urban Space. In Colquhoun, A. (Eds.), Modernity and the Classical Tradition: Architectural Essays, 1980-87. Cambridge, Mass: MIT-Press.

Collins, M., \& Clarke, P. (1998). Planning Research Programme: The Use of Density in Urban Planning. Washington. Department of the Environment, Transport and the Region.

Conzen, M.R.G. (1988). Morphogenesis, morphological regions and secular human agency in the historic townscape, as exemplified by Ludlow. In Denecke, D. y Shaw, G. (Eds.), Urban historical geography (pp. 255-261). Cambridge: Cambridge University Press.

Conzen, M.R.G. (1975). Geography and townscape conservation. In Uhlig, H., Lienau, C. (Eds). Anglo-German symposium in applied geography. Reprinted in Whitehand, J.W.R. (Ed.), The urban landscape: historical development and management: papers by Conzen, 1981, Institute of British Geographers Special Publication, No.13. Academic Press. London \& New York: Academic Press.

Conzen, M.R.G. (1968). The growth and character of Whitby. In Daysh, GHJ (Ed.) A survey of Whitby and the surrounding area (pp. 49-89). Shakespeare Head Press, Eton.

Conzen, M.R.G. (1960). Alnwick, Northumberland: A study in town-plan analysis. Institute of British Geographers Publication, 27 (George Philip, London).

Chueca, F. (1968). Breve historia del urbanismo. Madrid: Alianza Editorial. 
De Santiago, E. (2008). Madrid, 'ciudad única'. Pautas y lógicas espaciales recientes en la región madrileña. Urban, 12, 8-33.

Del Cerro, R. (1995). La calle y el agua en el Toledo del siglo XIX: propuestas y realidades urbanas. Toledo: Instituto Provincial de Investigaciones.

Dempsey, N., Brown, C., Raman, S., Porta, S., Jenks, M., Jones, C. \& Bramley, G. (2010). Elements of urban form. In Dimensions of the Sustainable Cities. Future City, 2 (pp. 21-51). London: Springer. Ding, W. (2013). Urban design needs urban morphology: A practitioner's viewpoint. Urban Morphology, 17(2), 120-123.

Duany, A. (2002). Introduction to the Special Issue: The Transect. Journal of Urban Design, 7(3), $251-260$.

Duany, A., Plater-Zyberk, E., \& Speck, J. (2000). Suburban Nation: The Rise of Sprawl and the Decline of the American Dream. New York: North Point Press.

Enguita, A. (Eds). (2008). La ciudad contemporánea. Análisis de su estructura y desarrollo. Madrid: CEIM \& CEOE.

European Enviromental Agency, EEA (2006). Urban sprawl in Europe. The ignored challenge (EEA Report, 10). Retrieved from https://www.eea.europa.eu/publications/eea_report_2006_10

European Union (2011). Cities of tomorrow. Challenging, vision, ways forward. European Commission, Directorate General for Regional Policy.

Escudero, L. (2018a). Procesos de urbanización difusos y estructuras urbanas fragmentadas: el caso de Toledo (Castilla-La Mancha, España). Ciudad y Territorio. Estudios Territoriales, 50(197), 517538.

Escudero, L. (2018b). La urbanización dispersa del circuito secundario de acumulación capitalista: Toledo (España). Ería, 3(38), 327-343.

Font, A. (2007). Morfologías metropolitanas contemporáneas de la baja densidad. In G. Indovina (Coord.), La ciudad de baja densidad: lógicas, gestión y contención (pp. 97-108). Barcelona: Diputación de Barcelona.

García, F. (2017). La forma urbana: un estudio de las periferias de las ciudades intermedias españolas a lo largo del siglo XX (Doctoral dissertation, Universidad Politécnica de Madrid, Spain). Retrieved from https://doi.org/10.20868/UPM.thesis.48683

García-Pablos, R. (1964). Los problemas urbanísticos de Toledo ante su futuro desarrollo económico. Madrid: Ministerio de la Vivienda, secretaría General Técnica. Conferencias y Discursos, 15. 
Gehl, J. (2006). La humanización del espacio urbano. La vida social entre los edificios. Barcelona: Editorial Reverte.

Gil, J., Beirao, J.N., Montenegro, N. \& Duarte, J. (2012). On the Discovery of urban typologies: data mining the many dimensions of urban form. Urban Morphology, 16(1), 27-40.

Griffin, A., \& Ford, L. (1980). A model of Latin American city structure. American Geographical Society, 70(4), 397-422.

Harper, C. (2013). Compaction, scale and proximity: an investigation into the spatial implications of density for the design of new urban housing (Doctoral dissertation, University of Westminster, United Kingdom). Retrieved from

https://westminsterresearch.westminster.ac.uk/download/b88d024fc55e37783269732e435e3b aa9538785fa47fe7ee2f8f68d3eled756e/62125364/Claire_HARPER_2013.pdf

Higueras, E. (2009) El reto de la ciudad habitable y sostenible. Madrid: Editorial DAPP.

Hillier, B. (1996). Space is the Machine. London: Cambridge University Press.

Jabareen, Y. (2006). Sustainable urban forms. Journal of Planning Education and Research, 2006, $26,38-52$.

Jacobs, A., \& Appleyard, D. (1982). Towards an urban design manifiesto (Working paper, 384). Institute of Urban and Regional Development. University of California. Berkeley. Retrieved from https://pdfs.semanticscholar.org/293a/15cd8ad1e63d3676e577dca120872a80e771.pdf

Jacobs, J. (2011). Muerte y vida de las grandes ciudades. Capitán Swing.

Jackson, L. (2003). The relationship of urban design to human health and condition. Landscape and urban planning, 64, 191-200.

Johnson, J. (1994). Geografía Urbana. Barcelona: Oikos-Tau.

Karimi, K. (1997). The spatial logic of organic cities in Iran and the United Kingdom. Procedings Space Syntax, 1st Symposium (pp. 1-17). London.

Kickert C., Berghauser, M., \& Merten, N. (2014). Surveying density, urban characteristics, and development capacity of station areas in the Delta Metropolis. Environment and planning B: planning and design, 41, 69-92.

Kropf, K. (2016). The Handbook of Urban Morphology. London: Wiley.

Kropf, K. (2011). Urbanism, politics and language: the role of urban morphology. Urban Morphology, $15,157-61$

Kropf, K. (2009). Aspects of urban form. Urban Morphology, 13(2), 105-20. 
Kyung, H., \& Kain, J.H. (2016). Compact cities are complex, intensive and diverse but: can we designing such emergent urban properties? Urban Planning, 1(1), 95-113.

Levy, A. (1999). Urban morphology and the problem of the modern urban fabric: some questions for research. Urban Morphology, 3(2), 79-85.

López de Lucio, R. (1999). La transformación de la ciudad en veinte años de ayuntamientos democráticos (1979-1999). Madrid: Ayuntamiento de Madrid, Gerencia Municipal de urbanismo.

López de Lucio, R. (1993). Ciudad y urbanismo a finales del siglo XX. Valencia: Universidad de Valencia Ediciones.

López de Lucio, R., \& Hernández, A. (1995). Los nuevos ensanches de Madrid. La morfología residencial de la periferia reciente (1985-1993). Madrid: Gerencia Municipal de Urbanismo del Ayuntamiento de Madrid.

López de Lucio, R., Adura, A., Bataller, J. J., \& Tejera, J. (2016). Madrid, 1900-2016. Guía de urbanismo y diseño urbano. Madrid: Ayuntamiento de Madrid.

López, J., Cerrone, D., \& Mannigo, K. (2017). Comparing two methods for urban complexity calculation using the Shannon-wiener index. Sustainable Development and Planning IX. In WIT Transactions on Ecology and The Environment, Vol 226. WIT Pressk. Retrieved from https://www. witpress.com/elibrary/wit-transactions-on-ecology-and-the-environment/226/36305

Madanipour, A. (2006). Roles and challenges of urban design. Journal of Urban Design, 17(2), 173-93.

Maller, A. (1998). Emerging urban form types in a city of the American Middle West. Journal of Urban Design, 3(2), 137-50.

Marat-Mendes, T. (2013). Sustainability and the study of urban form. Urban Morphology, 17, 123124.

Más, R. (1997). Periferias urbanas y nuevas formas espaciales. In R. Domínguez (Cood.), La ciudad. Tamaño y crecimiento (pp. 371-385). III Coloquio de Geografía Urbana. Antequera: Universidad de Málaga.

Moneo, R. (1982). El urbanismo contemporáneo 1950-1980. In AA.VV. Vivienda y urbanismo en España (pp. 199-215). Barcelona: Banco Hipotecario de España.

Montgomery, J. (1998). Making a city: urbanity, vitality and urban design. Journal of Urban design, 3(1), 93-116.

Moraleda, C., \& Peces, F.J. (1991). Toledo, barrio a barrio: Santa Bárbara. Toledo. 
Moudon, A. (1997). Urban morphology as an emerging interdisciplinary field. Urban Morphology, I, $3-10$.

Muelas, M., \& Parrilla, E. (2008). Plan de Ordenación Municipal de Toledo. Urban, 13, 34-67

Navascúes, P. (1983). Tipología de la casa toledana en el Renacimiento. En La maison de la ville à la Renaissance Recherches sur I'habitat urbain en Europe aux XVe et XVle siècles, Paris, 1983, 177-182.

Nedovic-Budic, Z., Knapp, G.J., Shahumyan, H., Williams, B., \& Slaev, A. (2016). Measuring urban form at community scale: case study of Dublin, Ireland. Cities, 55, 148-164.

Netto, V. (2017). The social fabric of cities. London \& New York: Routledge.

Oliveria, V. (2016). Urban Morphology. An introduction to the study of the physical form of the cities. Springer.

Oliveira, V. (2013). Morpho, a methodology for assessing urban form. Urban Morphology, 17, 149161.

Panerai, P., Castex, J., \& Depaule, J.C. (1986). Formas urbanas: de la manzana al bloque. Barcelona: Gustavo Gili.

Panerai, P., Demorgon, M., \& Depaule, J.C. (1999). Analyse urbaine. Marseilles: Edition Parentheses.

Parker, T. (1994). The land use-air quality linkage: How land use and transportation affect air quality. Sacramento: California Air Resources Board.

Passini, J. (1994). El espacio edificado en la edad media. Anales Toledanos, 31, 67-88

Pinho, P. \& Oliveria, V. (2009). Different approaches in the study of urban form. Journal of Urbanism: International Research on Placemaking and Urban Sustainability, 2(2), 103-125.

Pinzón, C. E. (2009) Mapping Urban Form: Morphology studies in the contemporary urban landscape (Doctoral dissertation, Technische Universiteit Delft, Netherlands). Retrieved from: https://repository.tudelft.nl/islandora/object/uuid\%3Ae9f69c50-ce09-4e14-87a0-

\section{0b24d46bc6d}

Prieto, P., Romero, V., Moyano, A., Solís, E., \& Coronado, J.M. (2018). Identificación, clasificación y análisis de las formas urbanas en ciudades medias: aplicación a las capitales provinciales de CastillaLa Mancha. Anales de Geografía de la Universidad Complutense, 38(1), 87-112.

Prosperi, D., Moudon, A., \& Claessen, F. (2009). The Question of Metropolitan Form: An Introduction. Metropolitan Form, Autumn 2009, pp. 1-4 Retrieved from 
https://www.researchgate.net/publication/42318283_The_Question_of_Metropolitan_Form_An_I ntroduction

Porres, J. (1971). Historia de las calles de Toledo. Toledo: Diputación provincial.

Porres, J. (1989). Toledo a través de sus planos. Toledo: Instituto Provincial de Investigación y Estudios Toledanos, Diputación Provincial.

Rodríguez-Tarduchy, M. J. (2011). Forma y Ciudad. En los límites de la arquitectura y el urbanismo. Madrid: Cinter.

Ruiz-Apilánez, B., Arnáiz, M., \& Ureña, J. M. (2015). Beyond Lively Streets. In L. Vaughan (Ed.), Suburban Urbanities: Suburbs and the Life of the High Street (pp. 130-152). London: UCL Press.

Santacruz, G. (2016). Arquitectura y urbanismo en la ciudad imperial y su provincia, durante el centenario de la Real Academia de Bellas artes y Ciencias Históricas de Toledo (1916-2016). TOLETVM, 61, 315-361.

Schwarz, N. (2010). Urban form revisited-Selecting indicators for characterising European cities. Landscape and Urban Planning, 96(1), 29-47

Sicca, P. (1981). Historia del urbanismo. Siglos XIV, XV, XVI, XVII, XVIII, XIX y XX. Madrid: Instituto de Estudios de Administración Local.

Siksna, A. (1997). The effects of block size and form in North American and Australian city centres. Urban Morphology, 1, 19-33.

Solá-Morales, M. (1997). Las formas de crecimiento urbano. Barcelona: Colección Arquitectura, UPC.

Solá-Morales, M. (1973). Las Formas de Crecimiento Urbano. Urbanística I 1971-72. Barcelona: Ediciones Universidad Politécnica de Cataluña.

Solís, E., Mohino, I., \& Ureña, J. M. (2018). Centralidad territorial y especialización funcional como guía para la intervención en municipios con conjunto histórico. El caso de la Región Urbana Madrileña. ACE: Architecture, City and Environment = Arquitectura, Ciudad y Entorno, 13(37), 99-132.

Solís, E., Ruíz-Apilánez, B., \& Ureña, J. M. (2012). Transformación del sistema urbano-territorial en la región central de la España peninsular. La emergencia de la región metropolitana policéntrica madrileña. Scripta Nova: Revista electrónica de geografía y ciencias sociales, 16, 387-424. Retrieved from http://www.ub.edu/geocrit/sn/sn-420.htm

Terán, M. (1951). Toledo. Estudio de Geografía Urbana. Trabajo de investigación inédito presentado a las oposiciones de Geografía de la Universidad Central celebradas en 1951. In M. Terán (2004). Ciudades de España. Madrid: Real Academia de la Historia. 
Terán, F. (1996). Calles y algo más que calles. Urbanismo, 29, 6-21.

Tsai, Y. H. (2005). Quantifying urban form: compactness versus 'sprawl'. Urban Studies, 42(1), $141-161$.

Torres, L. (1970). Ciudades hispanomusulmanas. Tomo I. Madrid: Instituto Hispano-Árabe de Cultura.

Urban Morphology Research Group. Glossary (1990). Retrieved from http://www.urbanform.org/glossary.html

Ureña, J. M., Solís, E., Ruiz-Apilánez, B. \& Mohíno, I. (2012). El hábitat unifamiliar en ciudades históricas de regiones metropolitanas policéntricas: el caso de Toledo. Cuadernos de Ingeniería, Arquitectura y Territorio, 13. Retrieved from

https://previa.uclm.es/cr/caminos/Publicaciones/Cuaderno_Ing_Territorio/Libros/cuaderno13/ CIAT_13.pdf

Vilagrasa, J. (1998). The study of urban form in Spain. Urban Morphology, 2(1), 35-44

Van Den Hoek, J. (2008). The MXI (Mixed-use Index) an instrument for anti-sprawl policy? Paper presented at the 44th ISOCARP Congress. Dalian, China.

Van Den Hoek, J. (2009). The Mixed Use Index (Mixed-use Index) as Planning Tool for (New) Towns in the 21st Century. In E. Stolk \& M. T. Brömmelstroet (Eds.), New Towns for the 21st Century: the Planned vs the Unplanned city (pp. 98-207). Amsterdam: SUN Architecture.

Vanderhaegen, S., \& Canters, F. (2017). Mapping urban form and function at city block level using spatial metrics. Landscape and Urban Planning, 167, 399-409.

Velasco, A. (2007). La parcela catastral en las Infraestructuras Nacionales de Datos Espaciales (NDSI) y en INSPIRE. Resultados del grupo de trabajo sobre el papel de la parcela catastral en Europa. Catastro, 60, 7-73.

Wall, E., \& Waterman, T. (2012). Arquitectura del paisaje. Diseño Urbano. Madrid: Nerea.

Whitehand, J. (1987). Urban morphology. In Pacione, M. (Ed.), Historical geography: progress and prospect. London: Croom Helm.

Whitehand, J., Gu, K., Conzen, M. P., \& Whitehand, S. M. (2014). The typological process and the morphological period: a cross-cultural assessment. Environment and Planning B: Planning and Design, 41, 512-533.

Ye, Y., \& van Ness, A. (2014). Quantitative tools in urban morphology: combining space syntax, spacematrix and mixed-use index in a GIS framework. Urban Morphology, 18(2), 97-118. 
Zárate, M. A. (1998). Forma urbana en Castilla-La Mancha. Espacio, Tiempo y Forma, Serie VI, Geografía, 11, 157-187. 